\title{
Explaining the Effects of Climate Elements in Tehran's Metropolis Air Quality
}

\section{ART ICLE INF O}

\section{Article Type}

Original Research

\section{Authors}

Ramezani R. ${ }^{1} M A$,

Alijani B.* $P h D$,

Reza B. ${ }^{1} P h D$

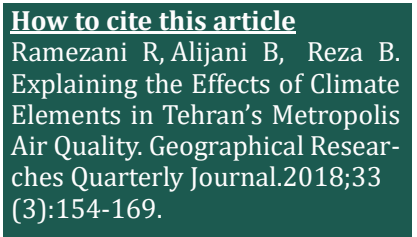

\section{A B S T R A C T}

Introduction and Background Atmospheric pollutants are elements whose high concentrations cause damage to the Earth's biological cycles, and its concentration is usually determined by concentrations of air pollutants such as nitrogen dioxide, sulfur dioxide, carbon monoxide, ozone and suspended particles. Air pollutants have changed the composition of air and affect the air quality of local, regional and global climate. Air quality is strongly influenced by climatic conditions, topography, automobiles and industries, transportation system and the type and amount of pollutants.

Aims The purpose of this study is to investigate the direct and indirect effects of climate elements on the quality and pollution of Tehran metropolitan air.

Methodology The research method is quantitative-analytical and the data also includes selected meteorological parameters and air pollution in Tehran. The path analysis method was used to study the effects of climate elements on air quality in Tehran metropolis. This method investigates the causal relations of direct and indirect effects and the total effect of each of the independent variables on dependent variables which is Tehran air quality and interprets the relationships and correlations observed between them. In the process of analyzing the path, a theoretical diagram based on the possible effects of variables relative to each other wll be considered as the initial assumption, and then after the path analysis, variables affecting the final graph of the path are specified and interpreted.

Conclusion The results of the research have shown that, given the wide and important performance of meteorological data in this study, we must consider the meteorological factor as a decisive parameter that has great control over many other factors affecting the air quality of Tehran. This factor has played a significant role in both direct and indirect effects on Tehran's air quality.

Keywords Path Analysis; Conceptual Model; Climate Elements; Air Quality; Tehran Metropolis

\begin{abstract}
*Department of Geography, Faculty of Geographical Sciences, Kharazmi University, Tehran, Iran ${ }^{1}$ Department of Geography, \& Science \& Research, Islamic Azad University, Tehran, Iran
\end{abstract}

\section{*Correspondence}

Address: Department of Geography, Literature and Humanities Faculty, Kharazmi University, Southwest Mofatheh Street, Tehran, Iran. Phone: 02186072716

Fax: 02186072789

bralijani@gmailıcom

\section{Article History}

Received: June 30, 2018

Accepted: October 29, 2018

ePublished: December 09, 2018

\section{CITATION LINKS}

[Abbasi Jebli; 2011] Investigating the air pollution process in ...; [Abbasi, et al.; 2013] Climatic factors of winter season affected ...; [Abedini; 1999] The effect of sustainability on the concentration ...; [Akbari, et al.; 2015] Monthly zonation of air pollution and its relationship ...; [Bidokhti \& Sharaeipour; 2010] Meteorological conditions of acute air ...; [Croxford, et al.;1996] Spatial distribution of urban pollution ...; [Doherty et al.; 2013] Impacts of climate change on surface ...; [Entezari; 2003] Statistical and synoptic study of tehran air ...; [Fayyaz; 2006] Track analysis, student ...; [Fenger; 1999] Urban air quality. Atmospheric ...; [Frank, et al.; 2000] Linking land use with household ...; [Isa Lo, et al.; 2011] Spatial ulnerability and air pollution ...; [Jacob \& Winner; 2009] Effect of climate change on air ...; [Javan Bakhat Amiri \& Khatami; 2012] Investigating the relationship ...; [Javid; 2012] Spatial distribution and seasonal ...; [Johnson \& Wichern; 1992] Applied multivariate mtatistical ...; [Mahoori;

2012] Path analysis training in ...; [Mohammadi \& Robati; 2009] The role of climatic parameters in the distribution ...; [Naghavi; 2013] Synoptic analysis of climatic elements ...; [Park, et al.; 2012] The visualization by analyzing the ...; [Peel, et al.; 2013] Impact of nitrogen and climate change ...; [Ren et al.; 2007] Influence of ozone pollution and climate ...; [Roshan, et al.; 2009] The effect of air pollution on climatic ...; [Safavi \& Alijani; 2006] Geographical factors investigating Tehran's ...; [Saligheh \& Kakhki Mahneh; 2015] Investigating the relationship between climate ...; [Schaub \& Paoletti; 2007] Introductory remarks to the special issue ...; [Schweitzer \& Zhou; 2010] Neighborhood air quality, respiratory health ...; [Taghavi; 2011] Time and spatial distribution of air pollution ...; [Taheri \& Hosseini; 2017] Pending particles, resources, measurements ...; [Vaseghi \& Zibaei; 2008] Prediction of air pollution in ...; [Zebardast \& Riazi; 2015] Indicators of the human environment and its ... 
Ramezani N. MA

Alijani B. PhD

Borna R. PhD

bralijani@gmail.com

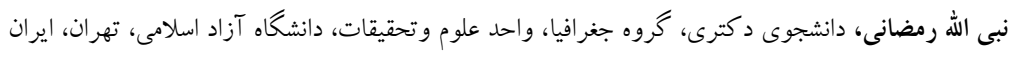

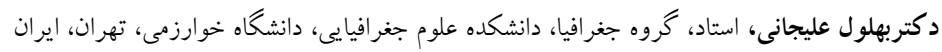

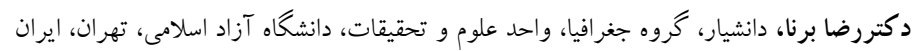

\title{
تبيين تأثيرات عناصر آبوهوايى در كيفيت هواى كلانشهر تهران
}

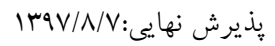 \\ دريافت مقاله:
}

DOI: 10.29252 /geores.33.3.154

جكيده

مقدمه: آلايندههاى جوى عناصرى هستند كه غلظت زياد آنها سبب صدمه به جرخههاى زيستى زمين مىشود و مقدار آن

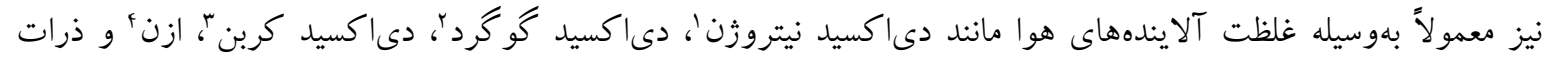

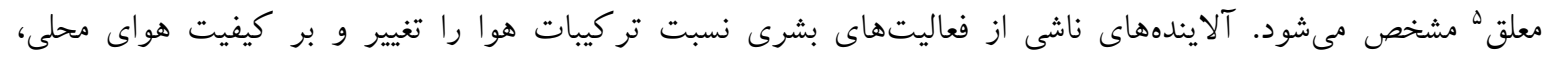

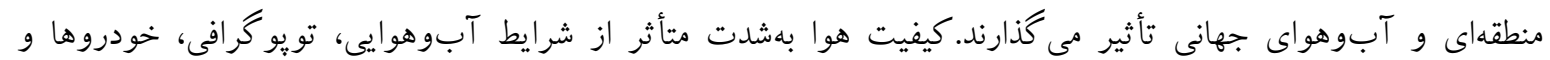
صنايع، سيستم حملونقل و نوع و ميزان آلايندها مها مىباشد.

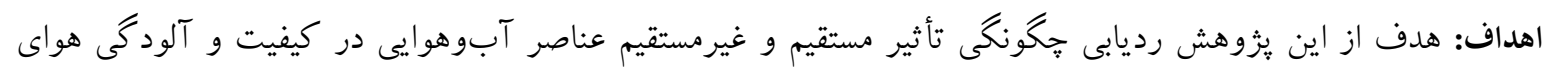
كلانشهر تهران مىباشد.

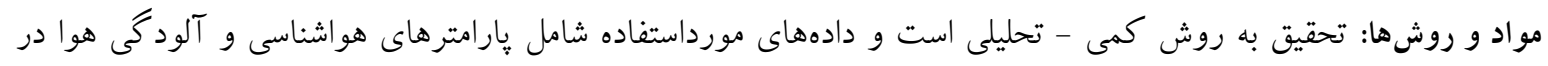
تهران مىباشند. بهمنظور بررسى اثرات عناصر اقليمى بر كيفيت هوا در كلانشهر تهران از روش روت تحليل مسير استفاده شد.

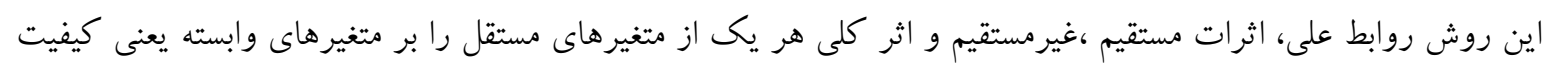

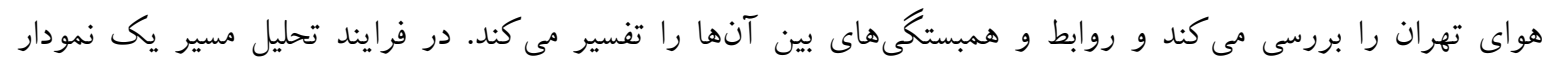

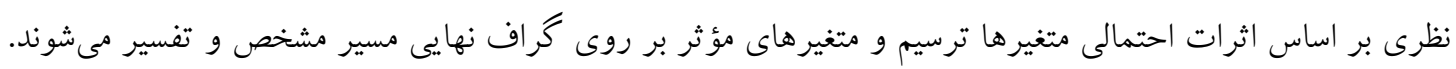

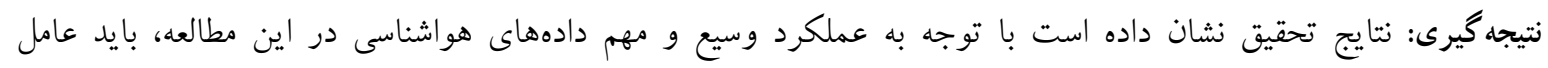

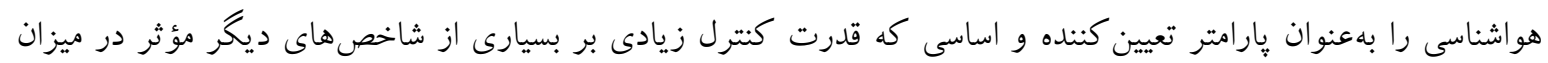

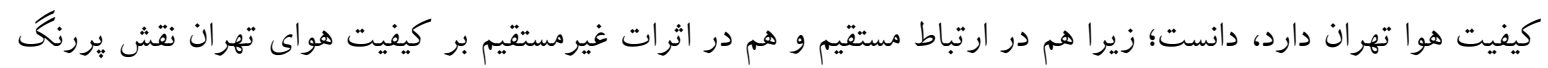
و بارزى ايفا كرده است.

وازگان كليدى: تحليل مسير، مدل مفهومى، عناصر آبوهوا، كيفيت هوا، كلانشهر تهران.

1 Nitrogen dioxide $\left(\mathrm{NO}_{2}\right)$

2 Sulfur dioxide $\left(\mathrm{SO}_{2}\right)$

3 Carbon dioxide $\left(\mathrm{CO}_{2}\right)$

4 Ozone $\left(\mathrm{O}_{3}\right)$

5 Particulate Matter (PM) 


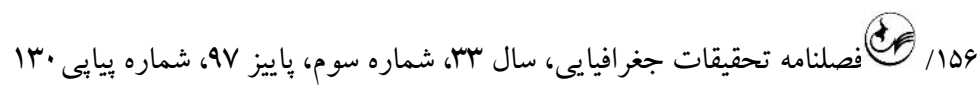

مقدمه

آلايندهاى جوى عناصرى هستند كه غلظت زياد آنها سبب صدمه به جرخههاى زيستى زمين مىشود و مقدار آن نيز

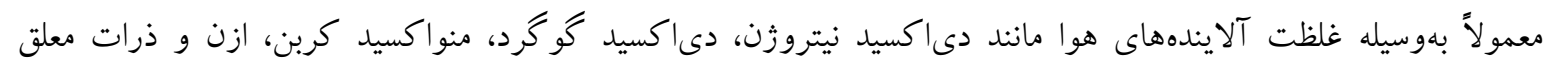

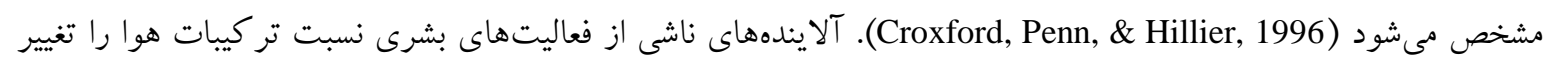

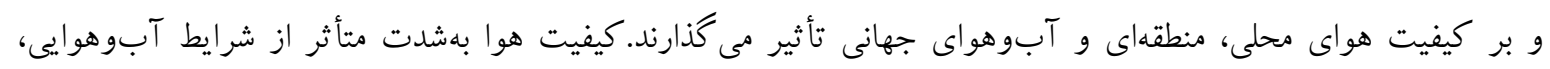

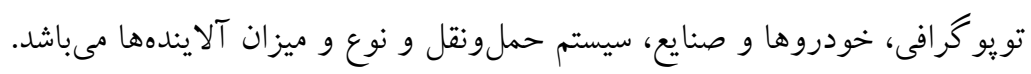

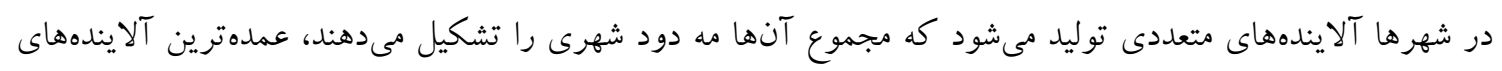

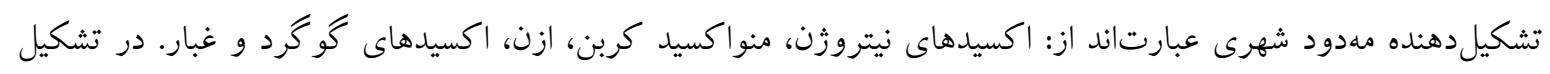

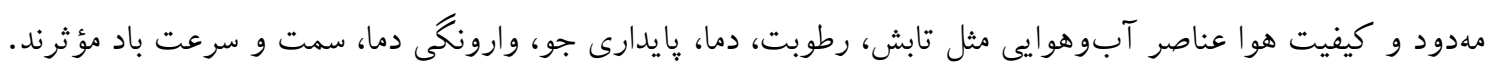

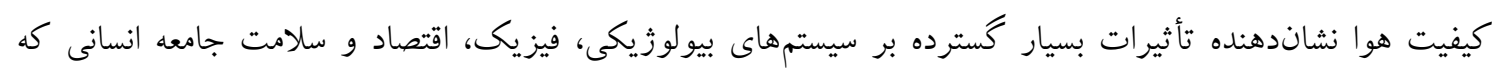

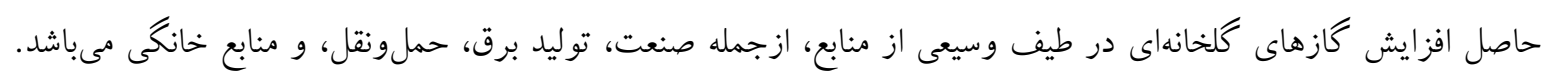

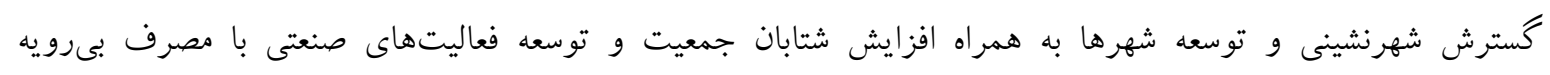

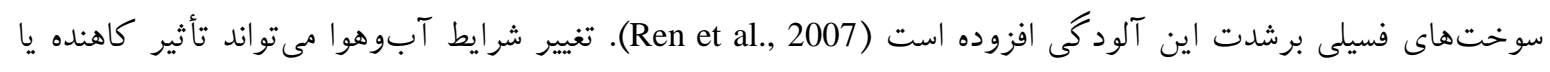

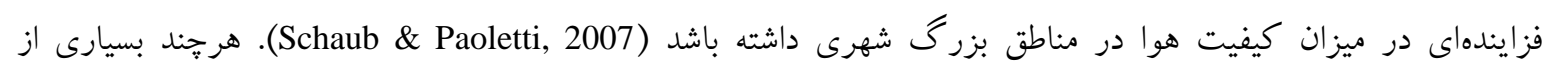

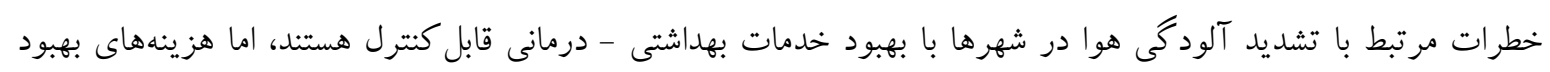

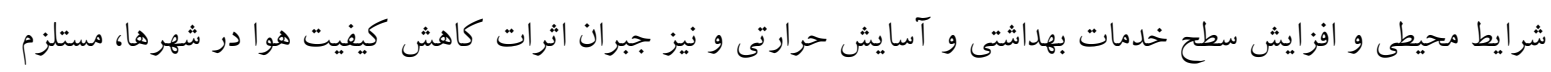

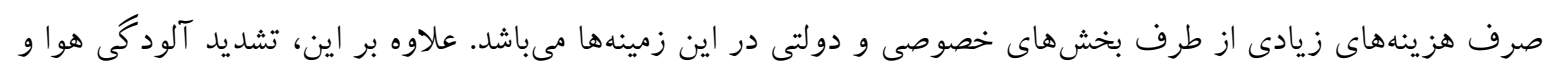

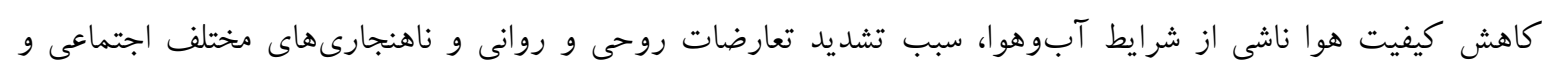
فرهنكى مى شود.

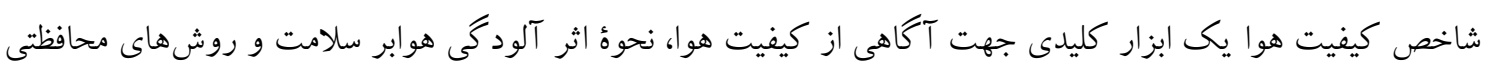

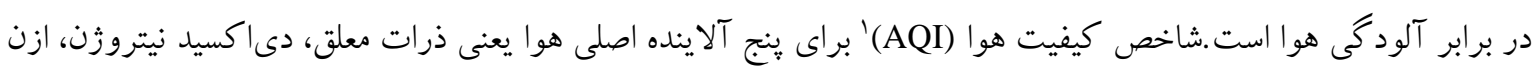

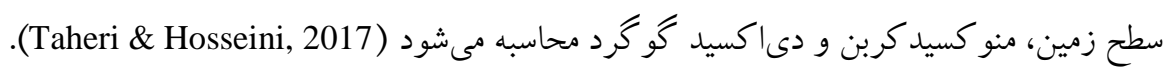

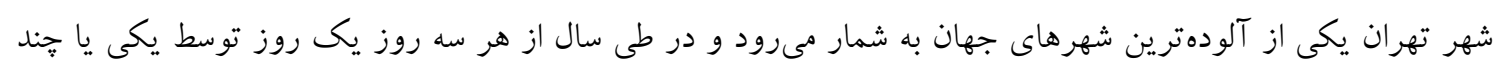

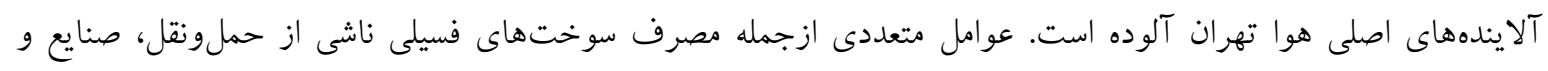

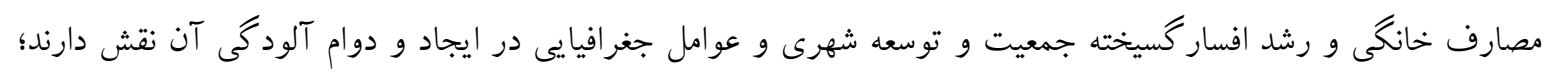

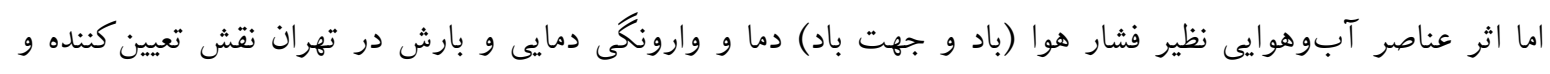

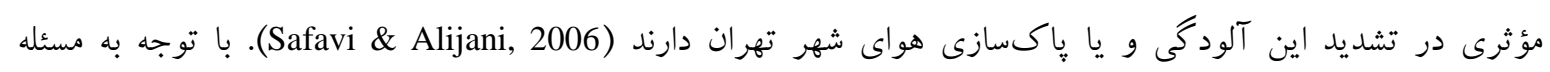

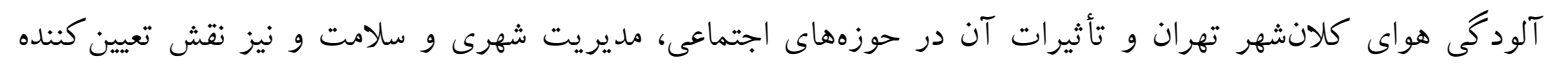

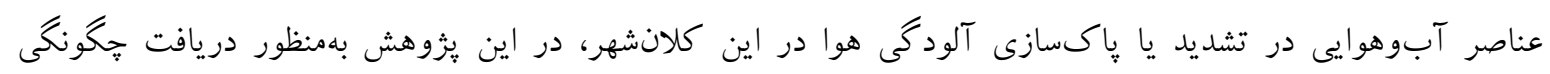

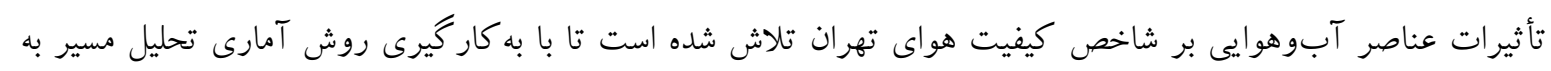

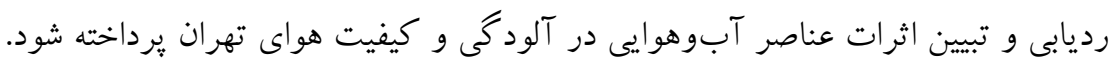


در طول سالهاى اخيرتلاشهاى بسيارى در بررسى روابط بين آلودگى هوا و پارامترهاى آب و هواشناسى انجامشده و

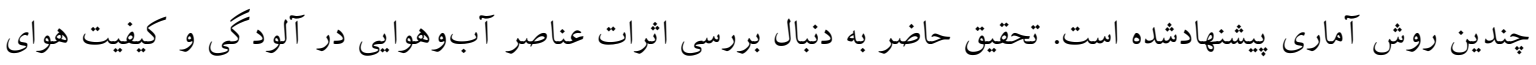

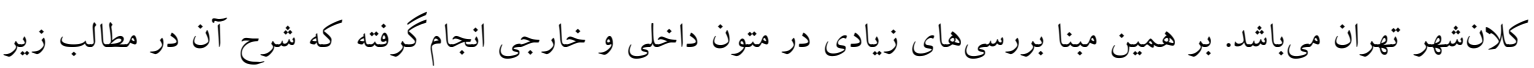
آمده است. بررسى اثر پايدارى شديد بر تمركز آلودگى هواى شهرهايى مانند تهران نشان مىدهد غلظت آلايندهاى جوى بهويزه

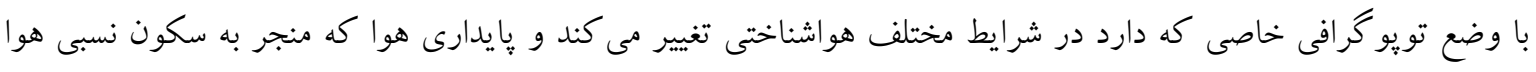

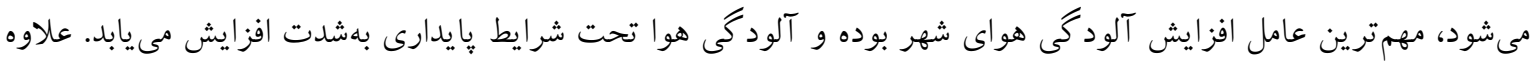

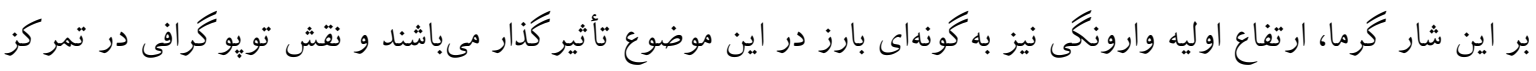

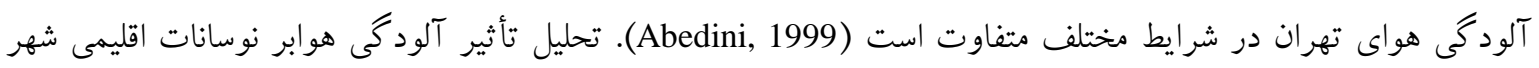

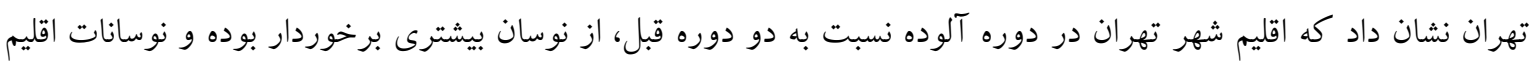

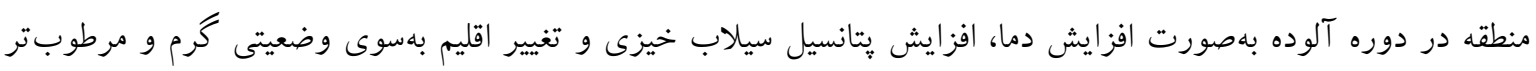

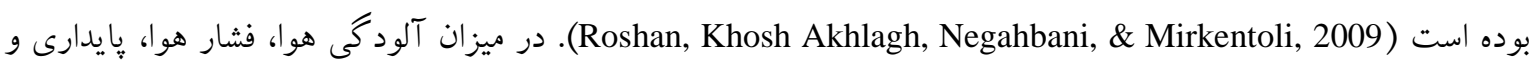

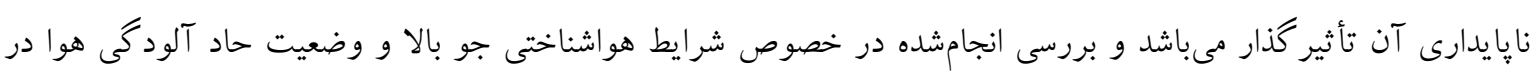

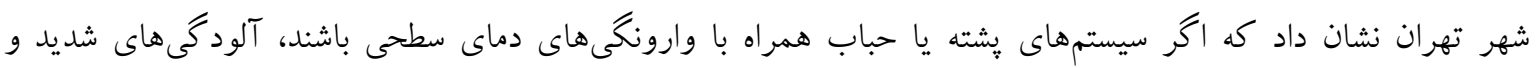

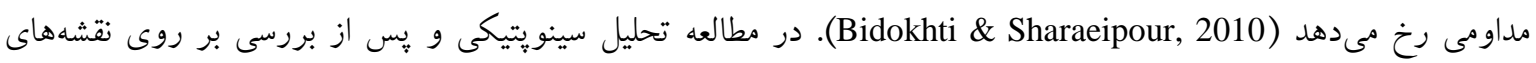

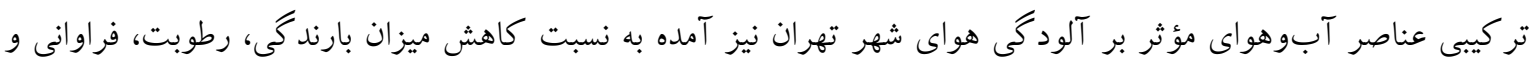

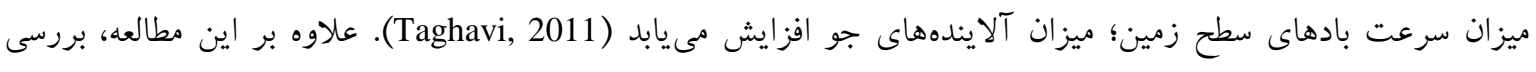

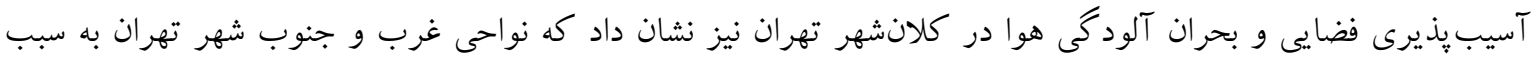

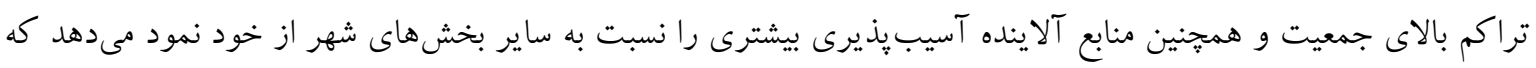

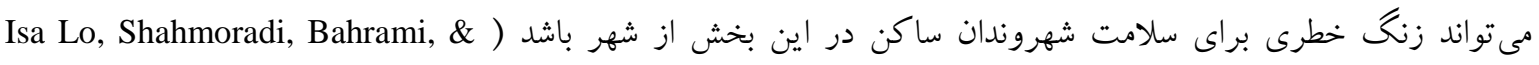

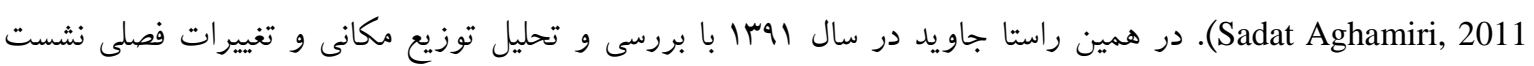

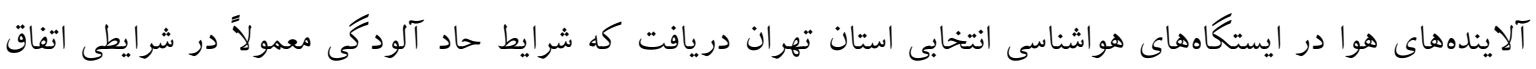

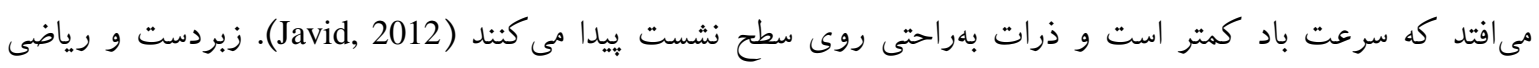

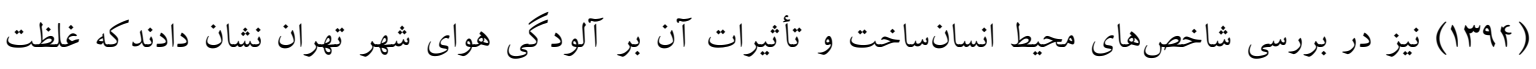

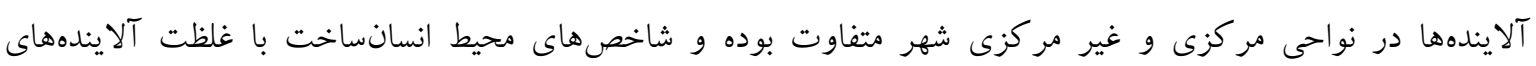

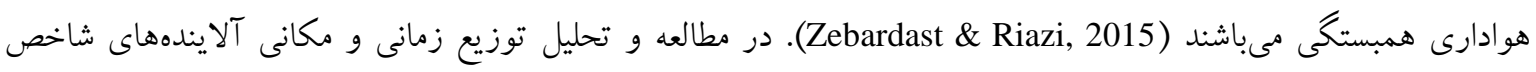

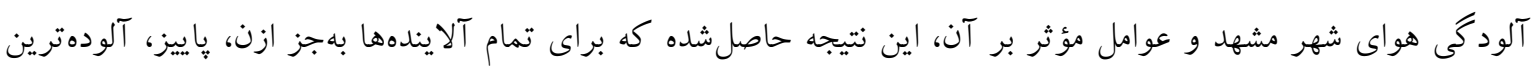

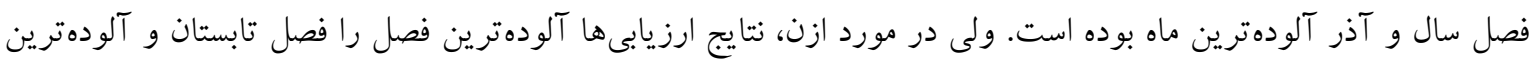

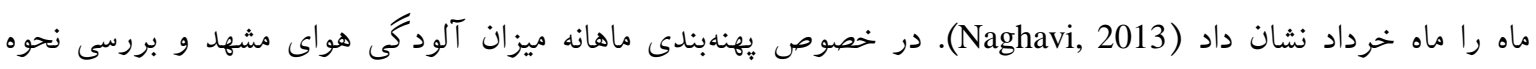

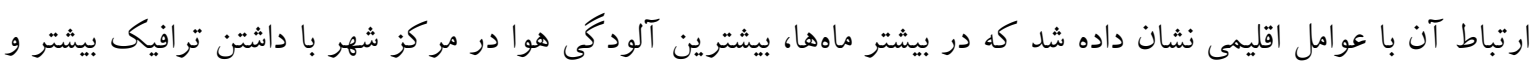

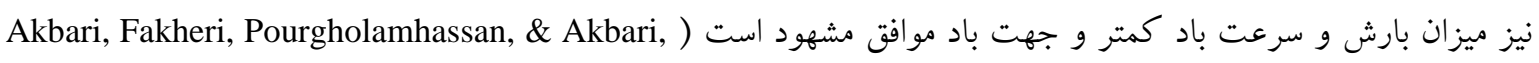

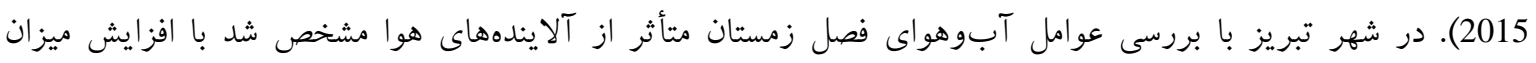

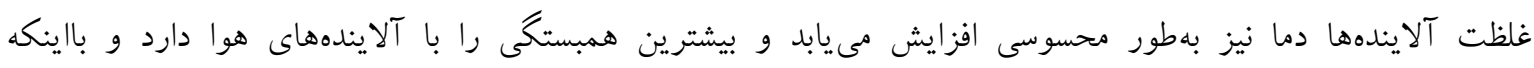

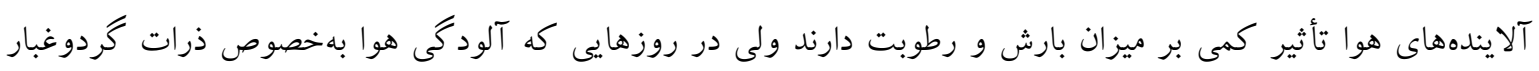




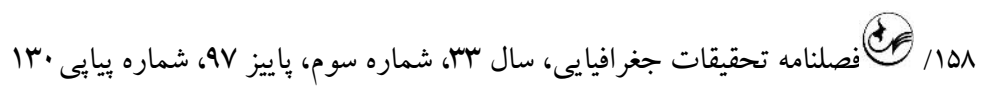
داراى غلظت بيشترى در هوا مىباشند، باعث افزايش بارش مى گردند ) Abbasi, Sari Saraf, \& Moghani Bileh Savar,

بررسى اثر پارامترهاى اقليمى در براكنش آلودگى هواى منطقه ويزه اقتصادى پِتروشيمى ماهشهر نشان داده است كه

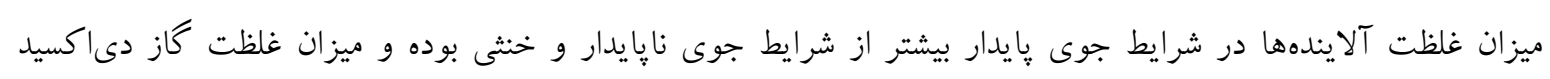

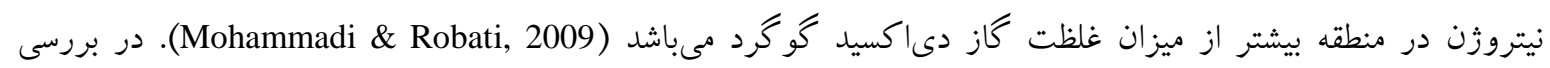

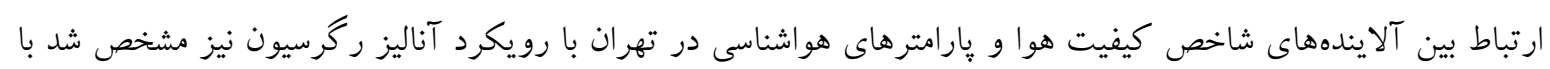

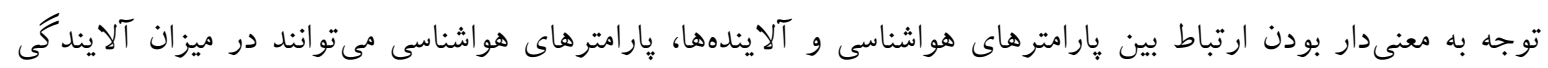

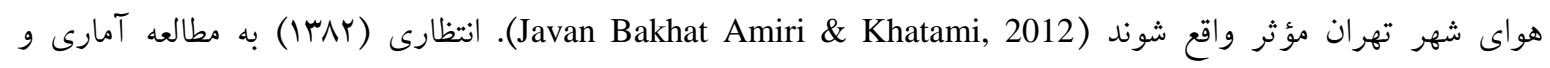

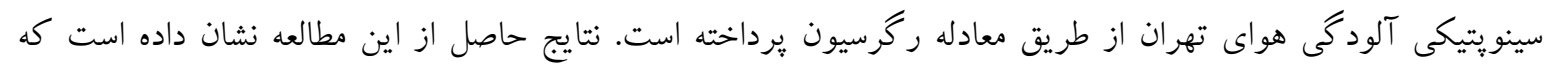

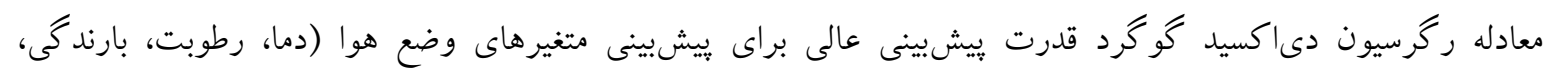

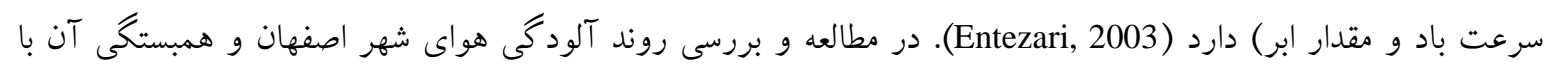

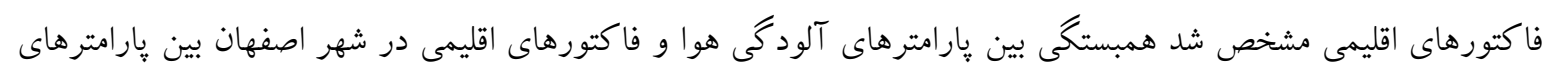

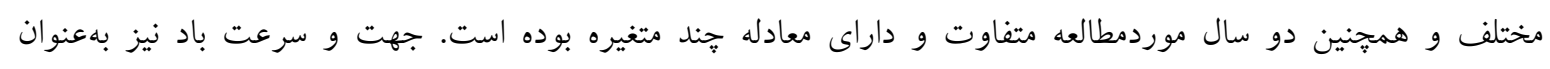

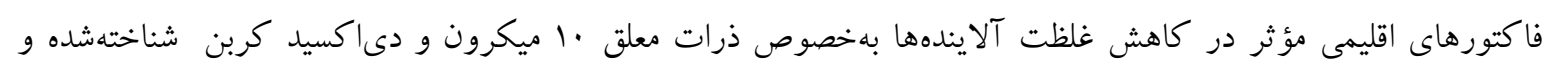

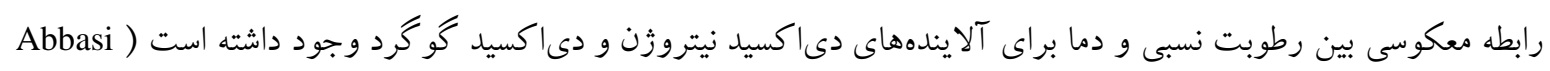

.(Jebli, 2011

در مطالعه و بررسى روابط بين عناصر آبوهوايى و نوسانات آلودگى هواى شهر مشهد با استفاده از سه مدل متفاوت

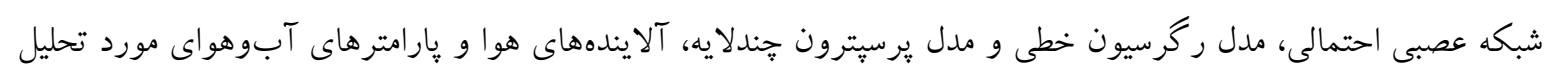

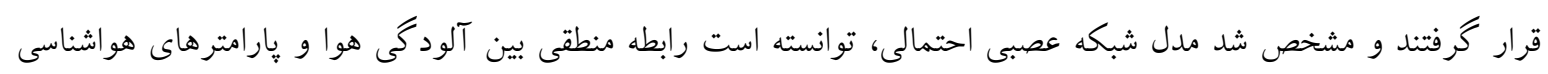

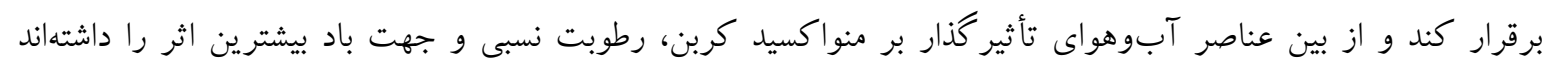

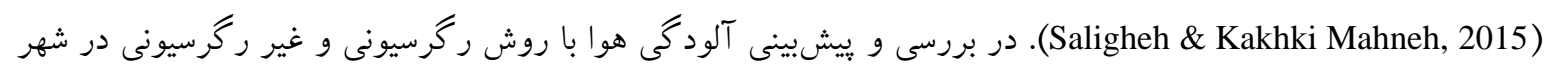

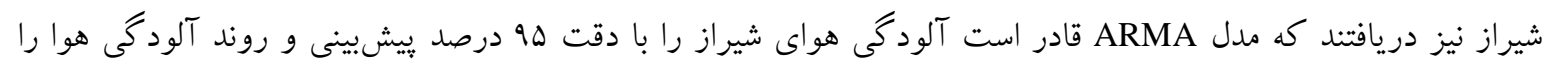
در آينده نزديك مورد ارزيابى قرار دهند (Vaseghi \& Zibaei, 2008).

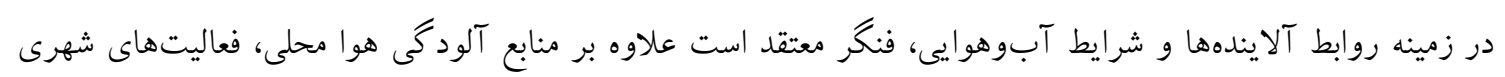

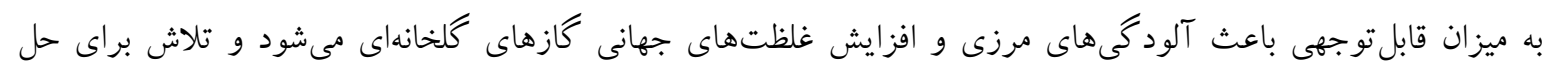

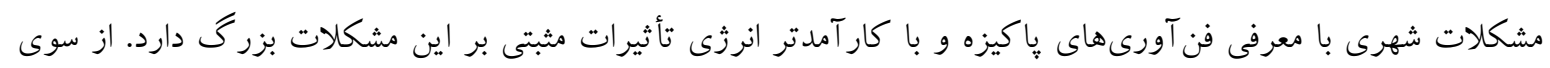

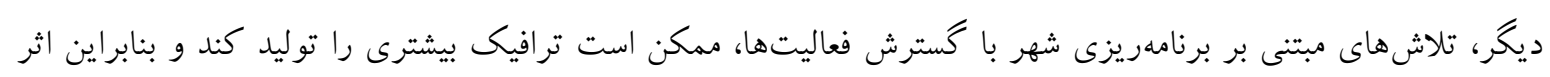

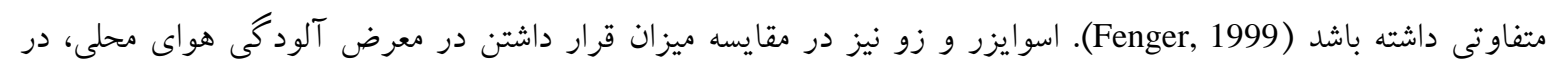

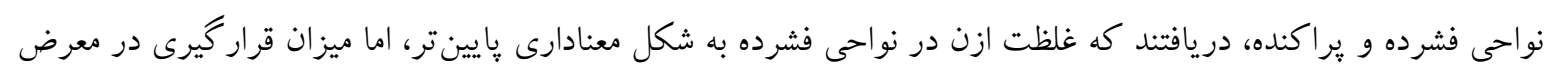

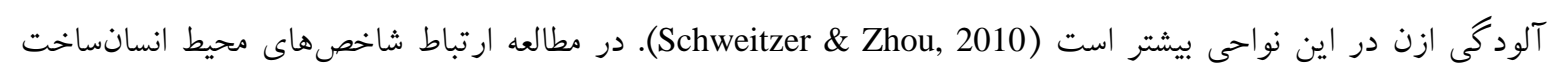

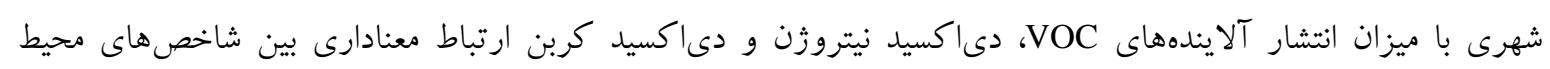

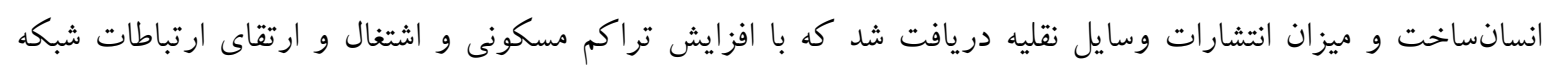

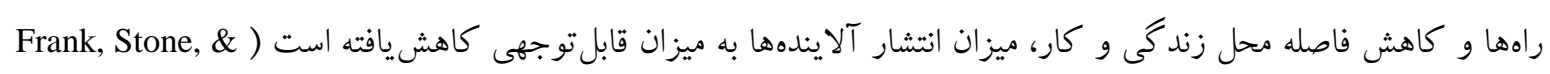


Bachman, 2000 ). جاكوب و وينر نيز بامطالعه اثرات شرايط آبوهوا در كيفيت هوا نشان دادند كه تغيير شرايط

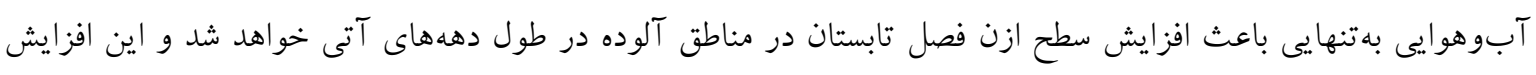

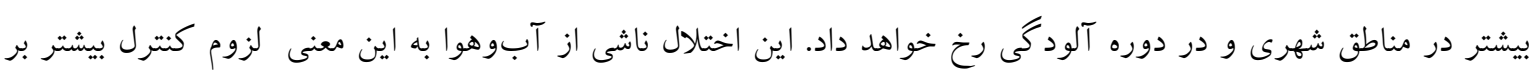

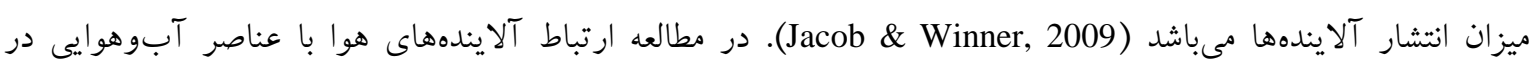

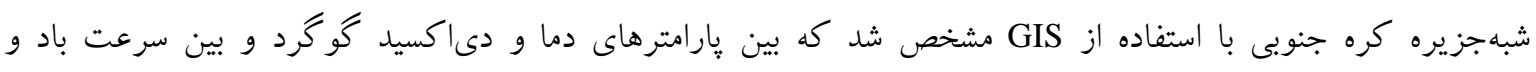

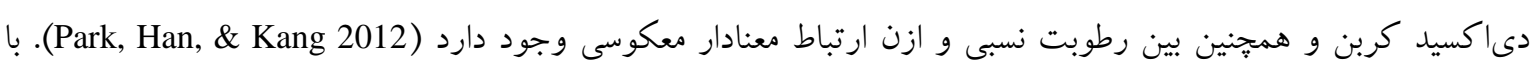

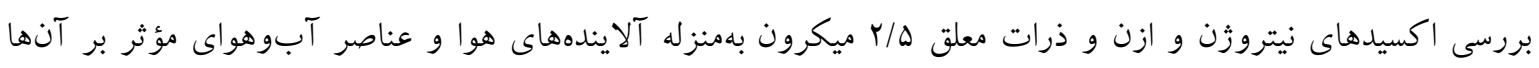

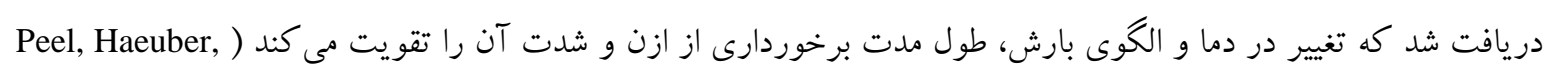

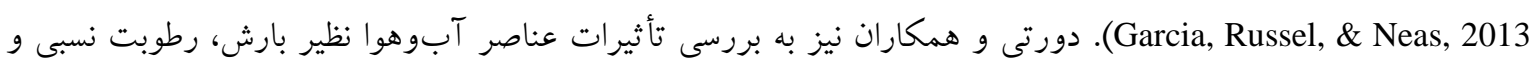

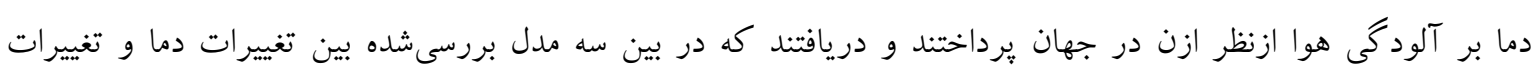

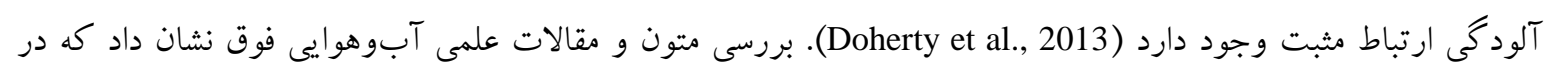

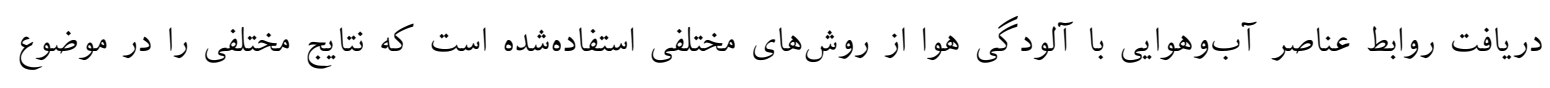

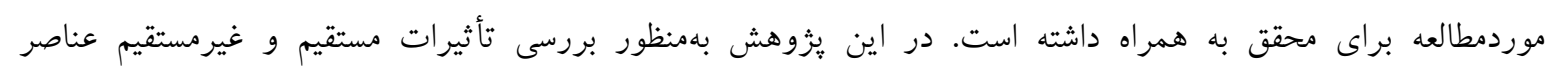

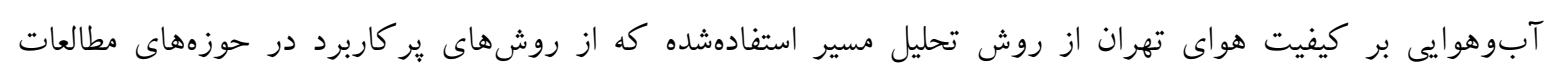

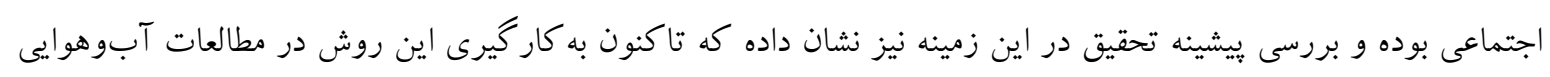

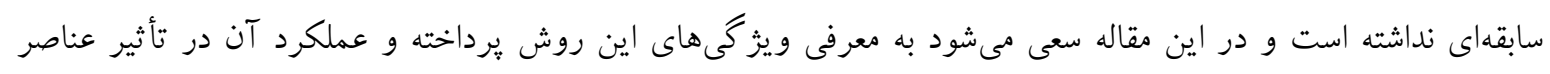
آبووهوايى بر كيفيت هواى تهران موردبررسى قرار گيرد.

دادهها و روش كار

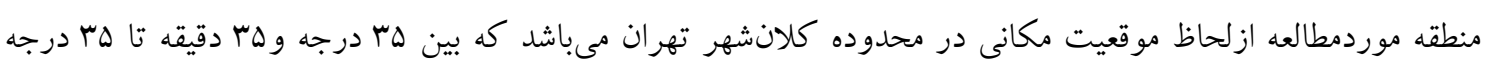

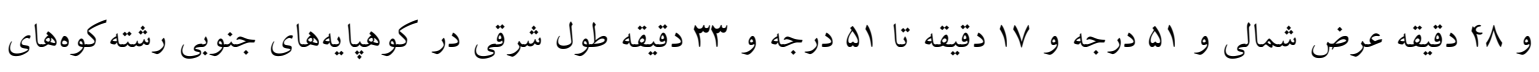

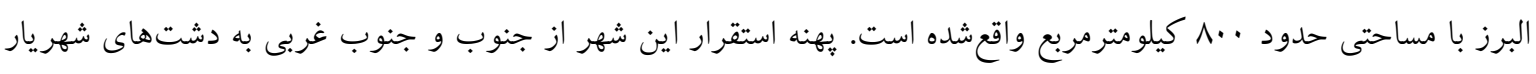

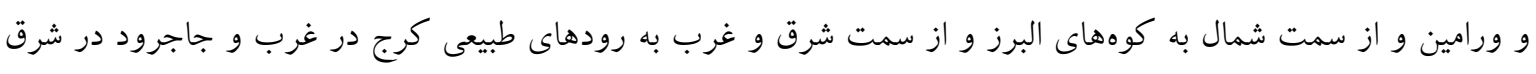

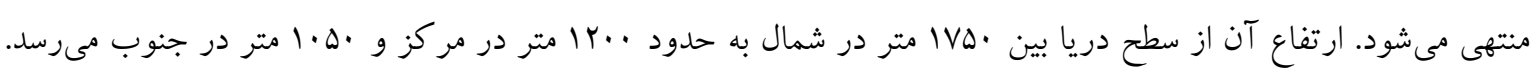

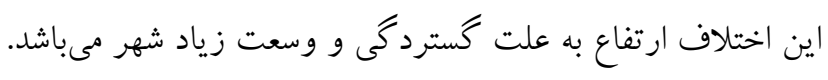

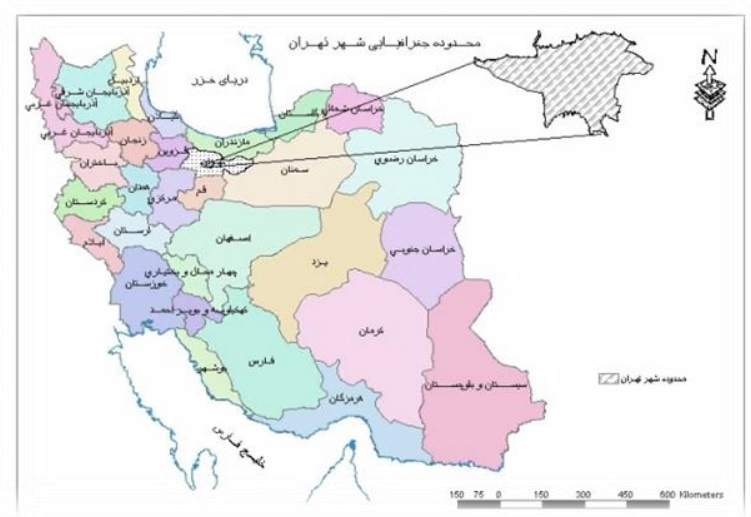

شكل ا - موقعيت جغرافيايى كلانشهر تهران 
19.

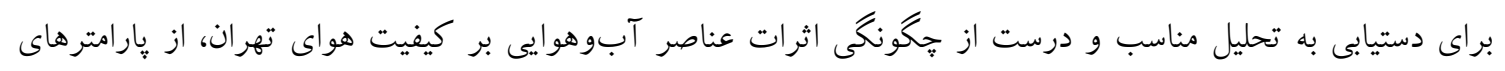

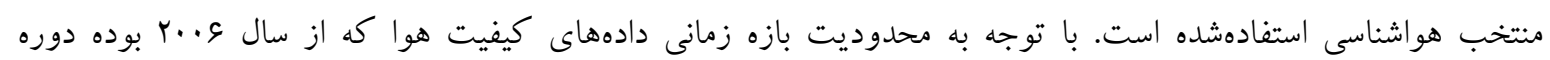

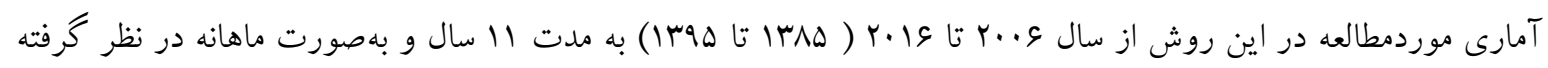

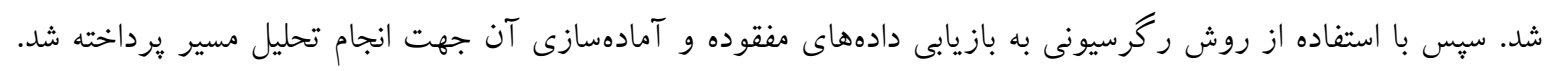

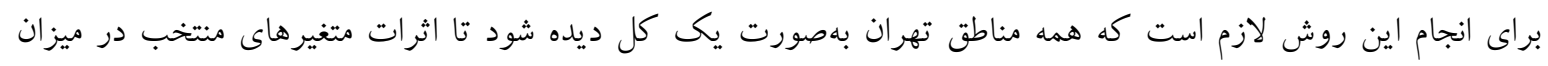

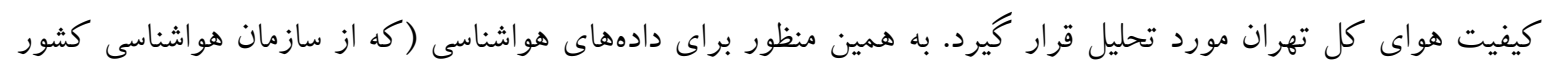

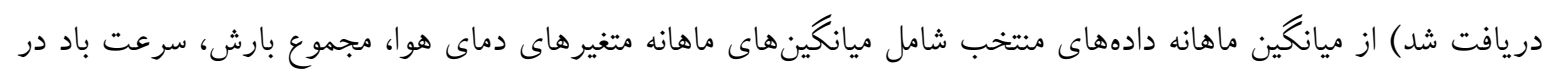

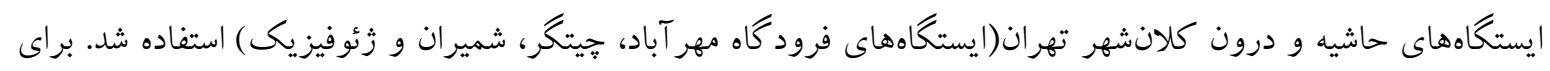

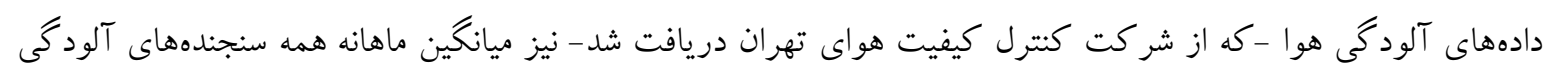

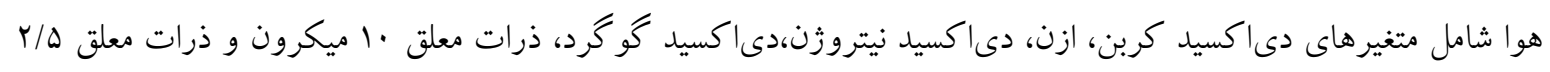
ميكرون در نظر كرفته شد. شاخص كيفيت هوا، شاخصى جهت اطلاعرسانى و ييشبينى روزانه كيفيت هوا مىباشد كه كيفيت هوا و ميزان ارتباط

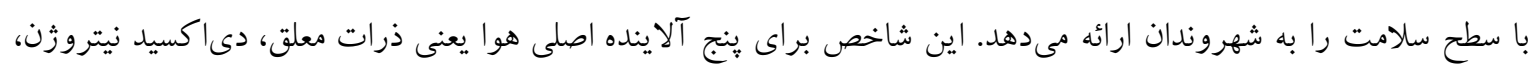

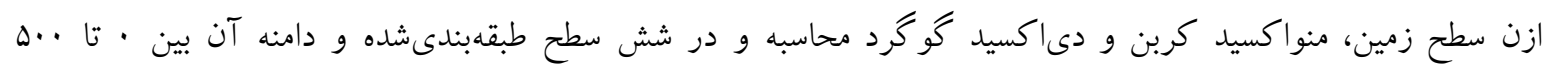
مىباشد (شكل r). هرجه مقدار اين شاخص بالاتر باشد از كيفيت هوا كاسته مى مُشود (Taheri \& Hosseini, 2017).

\begin{tabular}{|c|c|}
\hline AQI & كيفيت هوا \\
\hline $0-50$ & 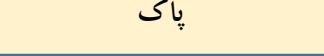 \\
\hline $51-100$ & ساله ( متو سط) \\
\hline 101-150 & ناسالم براى گروه هاى حساس \\
\hline 151-200 & ناسالم \\
\hline 201-300 & بسيار ناسالم \\
\hline $301-500$ & خطر ناكى \\
\hline
\end{tabular}

شكل - شاخص كيفيت هوا در شر ايط مختلف ( شركت كنترل كيفيت هواى شهردارى تهران)

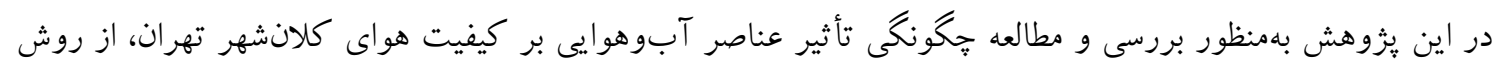

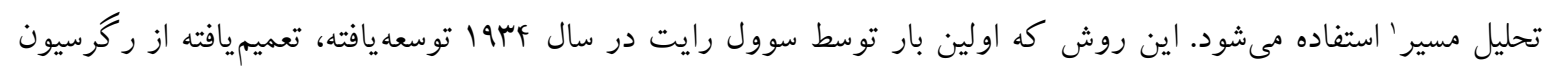

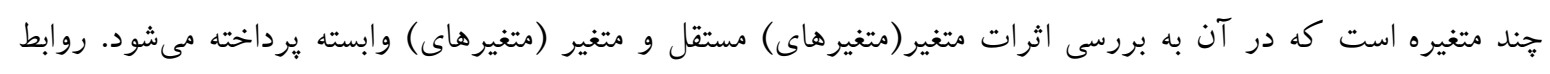

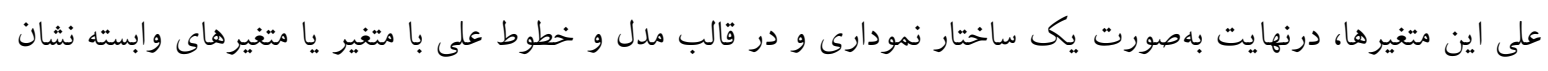

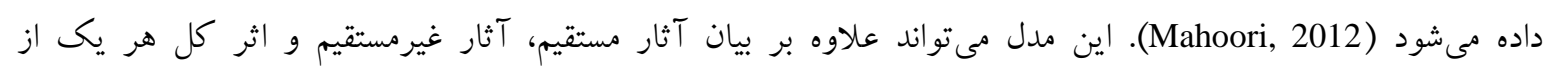

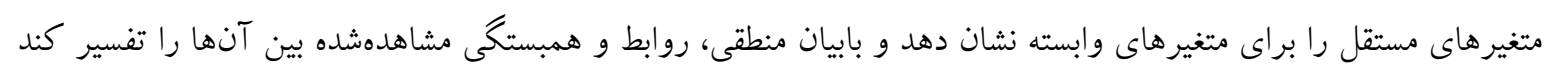

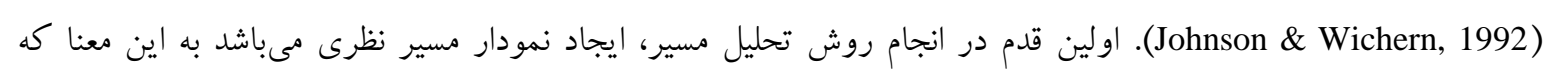

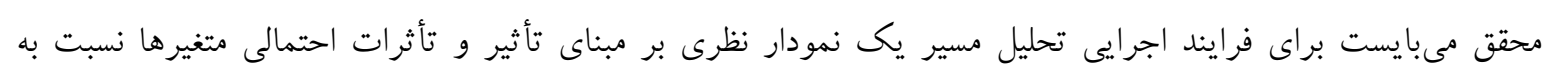


همديخر بهعنوان فرض اوليه ايجاد كند و سبس بعد از تحليل مسير، متغيرهاى خنثى را حذف و متغيرهاى تأثير كذار را در نمودار نهايى مسير بررسى كند (Fayyaz, 2006).

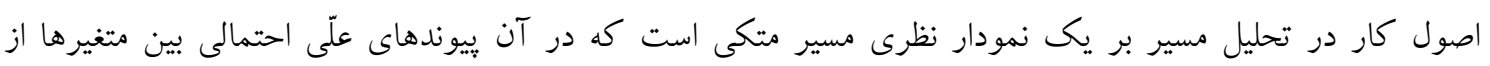

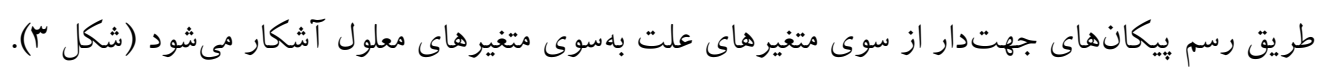

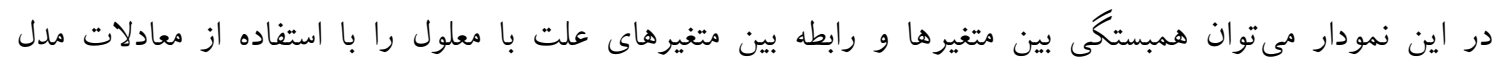

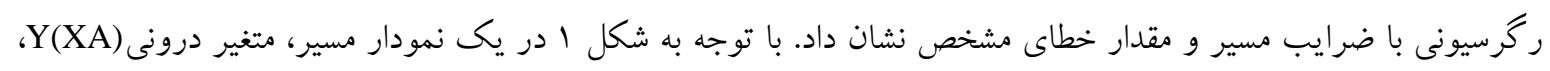

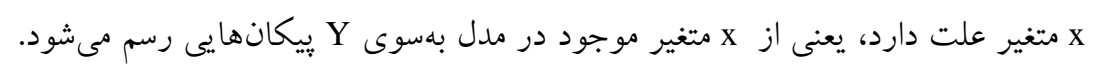

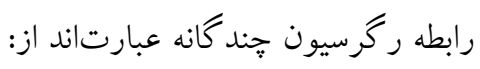

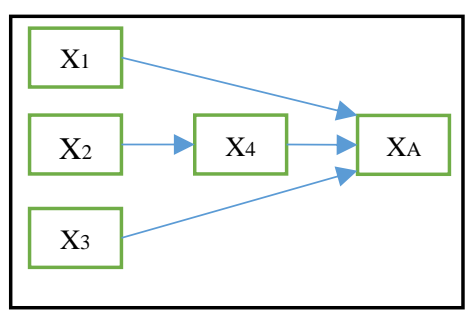

$Y=b_{0}+b_{1} x_{1}+b_{2} x_{2}+\cdots b_{r} x_{r}+e$

رابطه (1)

شكل r- نمونه نمودار مسير با ب متغير

كه Y متغير معلول،

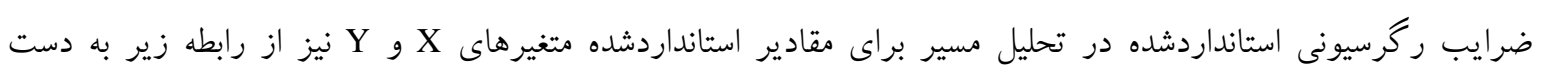
مى آيد.

$$
P x y_{i}=b_{i} \frac{s_{x i}}{s_{y}}
$$

كه در اين رابطه S S انحراف استاندارد متغير بر اساس ضرايب مسير عبارتند از:

$$
\begin{aligned}
& Z=P x y_{1} Z_{1}+P x y_{2} Z_{2}+\cdots P x y_{i} Z_{x}+e_{i} \\
& \text { رابطه (r) }
\end{aligned}
$$

كه در اينجا Z يك متغير بيرونى،

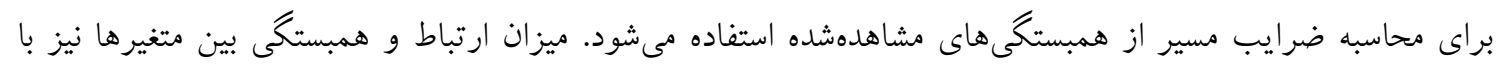

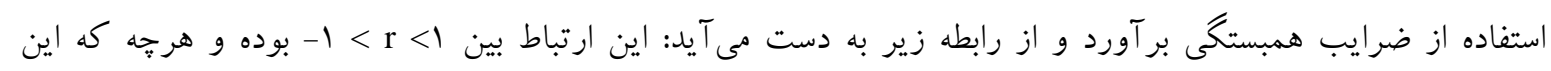

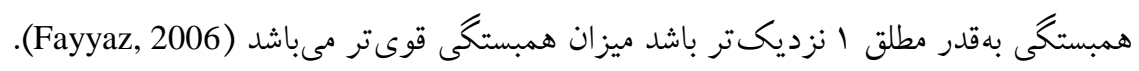

$$
r_{z z}=\frac{1}{N} \sum Z_{x}
$$

رابطه (F)

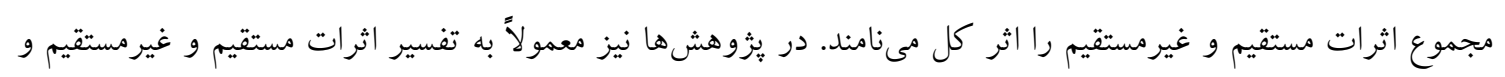

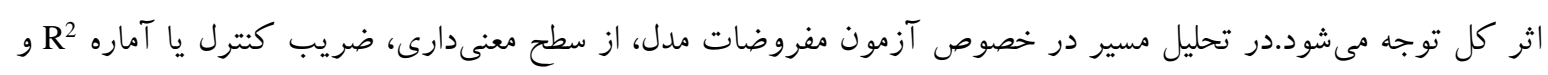

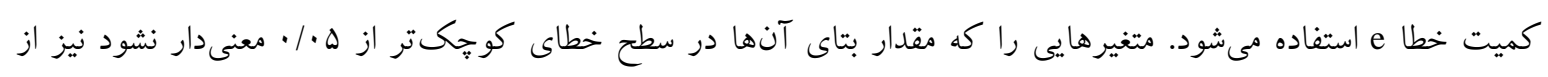

$$
\text { مدل حذف مىشوند. }
$$

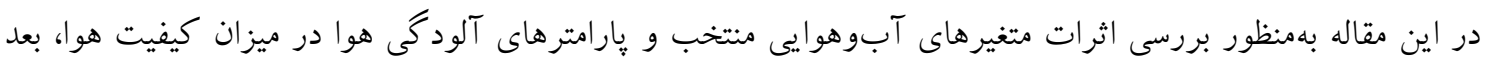

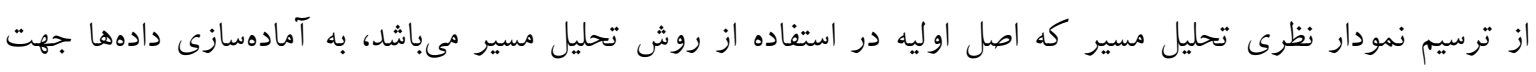




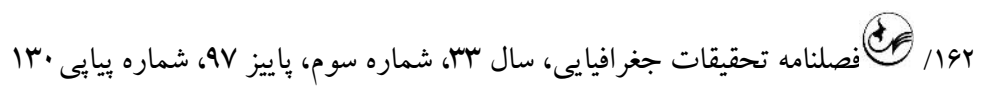
استفاده از روش تحليل مسير يرداخته مىشود؛ سِّ با توجه به ميزان همبستخى دادهها، ضرايب كنترل، سطح معنىدارى و

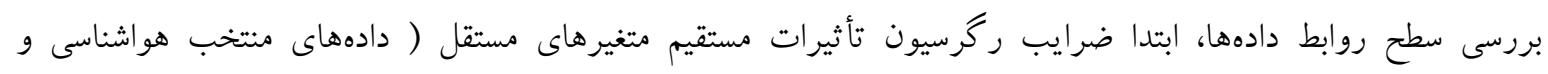

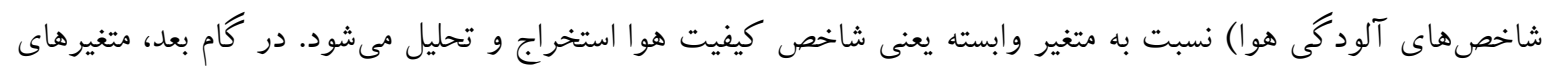

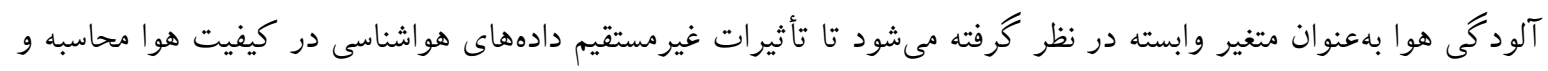

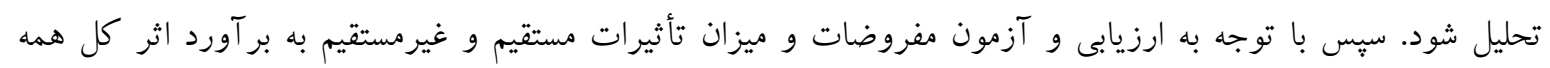

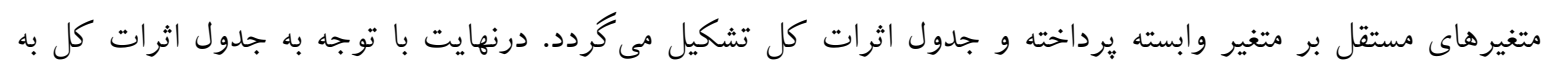

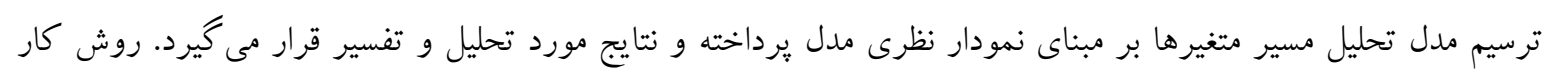

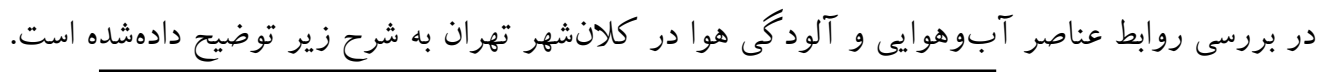

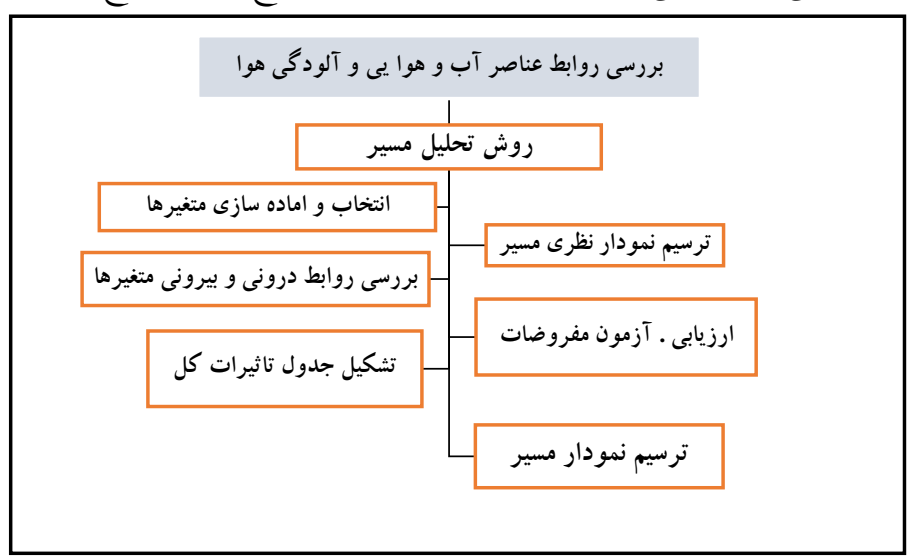

شكل †- روش كار در بررسى روابط تغيير آبوهوايى و آلودَى هوا

شرح و تفسير نتايج

بر مبناى روش كار مطرحشده، براى انجام تحليل مسير و بررسى روابط على متغيرهاى تأثير كذار در كيفيت هواى تهران

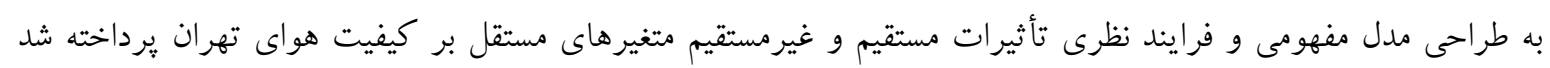

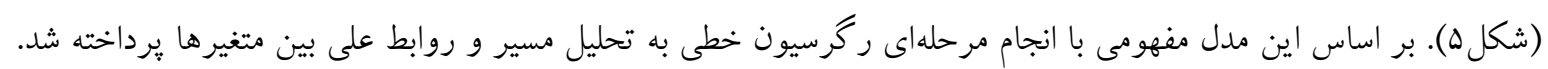

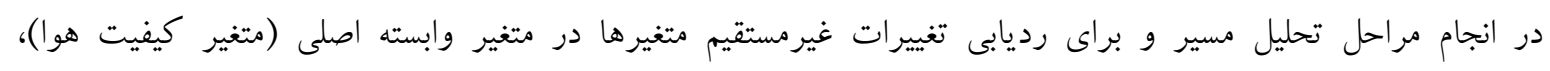

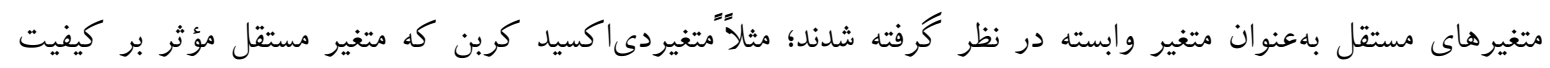

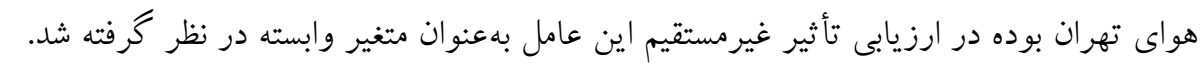

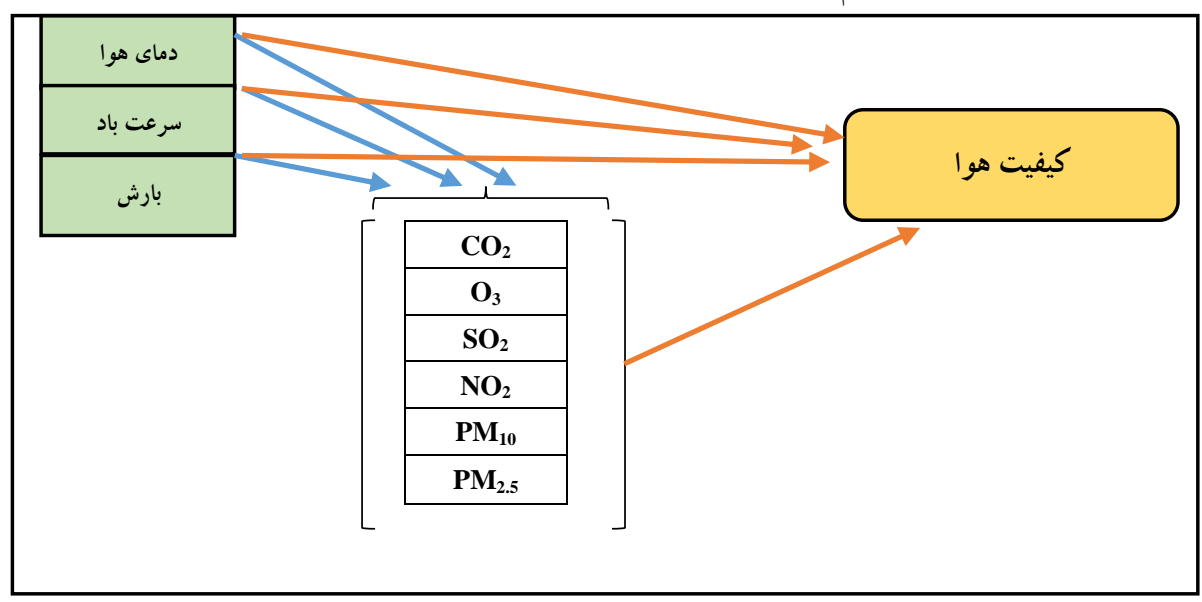

شكل ه - مدل مفهومى تحليل مسير اثرات بارامترهاى هواشناسى و آلودكى هوابر كيفيت هوا 
تبيين تاثيرات عناصر آبووهوايى در كيفيت هواى كلانشهر تهران/بان|

DOI: $10.29252 /$ geores.33.3.154

با توجه به مدل مفهومى طرحشده (شكله)، در كام نخست، متغير كيفيت هوا بهعنوان متغير وابسته نهايى و متغيرهاى

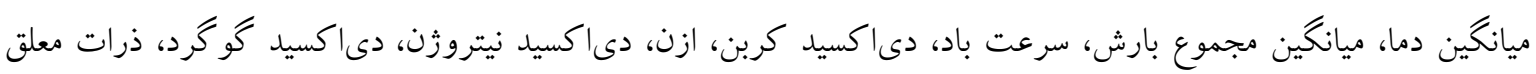

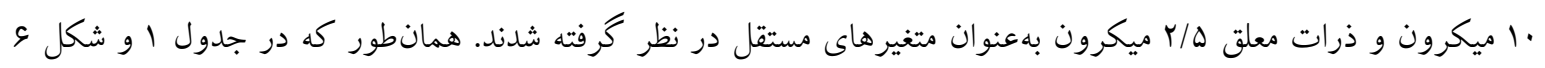

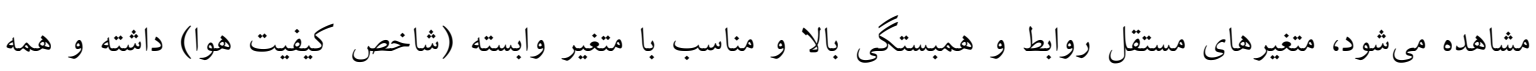

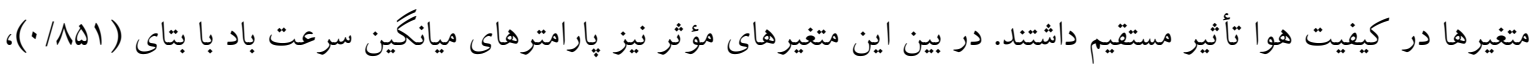

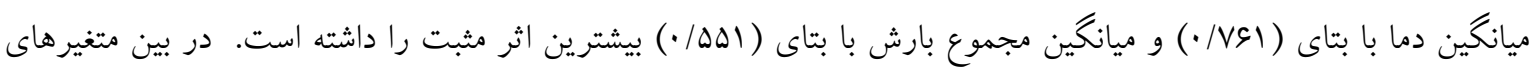

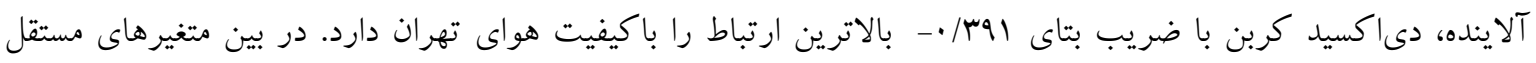

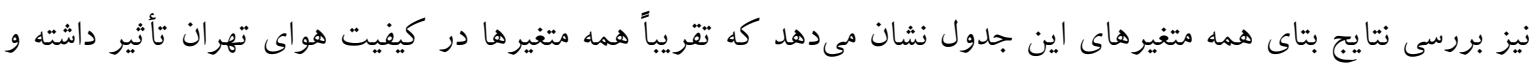

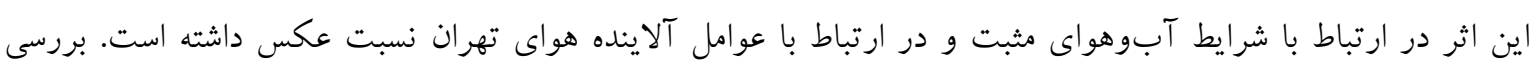

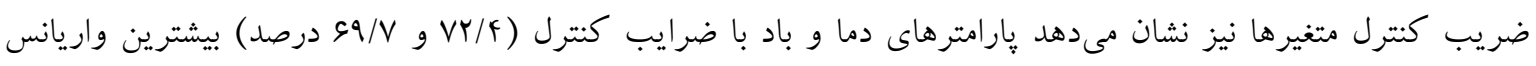
تغييرات شاخص كيفيت هوا را كنترل مى كنند.

جدول 1 - نتايج حاصل از تحليل مسير عوامل اثر كذار بر روى كيفيت هواى تهران

\begin{tabular}{|c|c|c|c|c|c|c|}
\hline \multirow[t]{2}{*}{ معنى دارى } & \multirow[t]{2}{*}{ كنترل ضريب } & \multirow{2}{*}{$\begin{array}{c}\text { ضرايب رگرسيونى استانداردشده } \\
\text { Beta } \\
\text { Beta }\end{array}$} & \multicolumn{2}{|c|}{ ضرايب رگرسيونى } & \multirow[t]{2}{*}{ ضمبيتى ضي } & \multirow[t]{2}{*}{ متغيرهاى مستقل } \\
\hline & & & Std. Error & $\mathrm{B}$ & & \\
\hline$\cdot / \cdot 4$ & $V r / f$ & $\cdot|V \varepsilon|$ & /.rr & .1 .94 & $\cdot / \wedge \Delta \mid$ & ميانگين دما \\
\hline$\cdot / \cdot \mu \Lambda$ & $s T / \mu$ & $\cdot / \Delta \Delta 1$ & $\cdot / \cdot F V$ &.$- / \cdot \cdot 9$ & $\cdot /$ VA9 & ميانكين مجموع بارش \\
\hline$\cdot / \cdots$ & $89 / V$ & $\cdot|\Lambda \Delta|$ & $\% r V$ & - & $\cdot / \Lambda \mu_{\Delta}$ & ميانگين سرعت باد \\
\hline 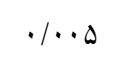 & $\Delta V / q$ & $-\cdot / r q 1$ & $\cdot / \cdot \wedge 1$ & ( ) & $-\cdot|V s|$ & دى اكسيد كربن \\
\hline . & $s 9 / 4$ & $-\cdot / 1 \wedge \varepsilon$ &.$/ .14$ & $-\cdot / 4 \cdot \Delta$ & $-\cdot / 1 / \Delta$ & 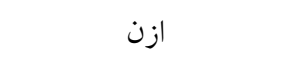 \\
\hline.$/ .14$ & $59 / 4$ &.$- / Y M F$ & $\cdot / \cdot 19$ &.$|M Y|$ & $-\cdot / V \cdot r$ & دىاكسيد نيتروزن \\
\hline$\cdot 1 \cdot 0$ & $F V / T$ & $-\cdot /$ KYq &.$/ 1 Y \Delta$ & $\mid$ & $-\cdot / 8 \Lambda \Lambda$ & دىاكسيد گو گرد \\
\hline . & $\Delta f / 9$ & (- &.$/ 11 r$ &.$/ 118$ & $-\cdot / V \& I$ & ذرات معلق · اميكرون \\
\hline.$/ \cdot \mu \Lambda$ & $F r / q$ & $-\cdot / \mathrm{kr}$ & $\cdot / \cdot \mathrm{vq}^{2}$ &.$/ .9 \mathrm{~V}$ & $-\cdot / 8 \Delta \Delta$ & ذرات معلق ه/ r ميكرون \\
\hline & & & & & كيفيت هوا & متغير وابسته \\
\hline
\end{tabular}

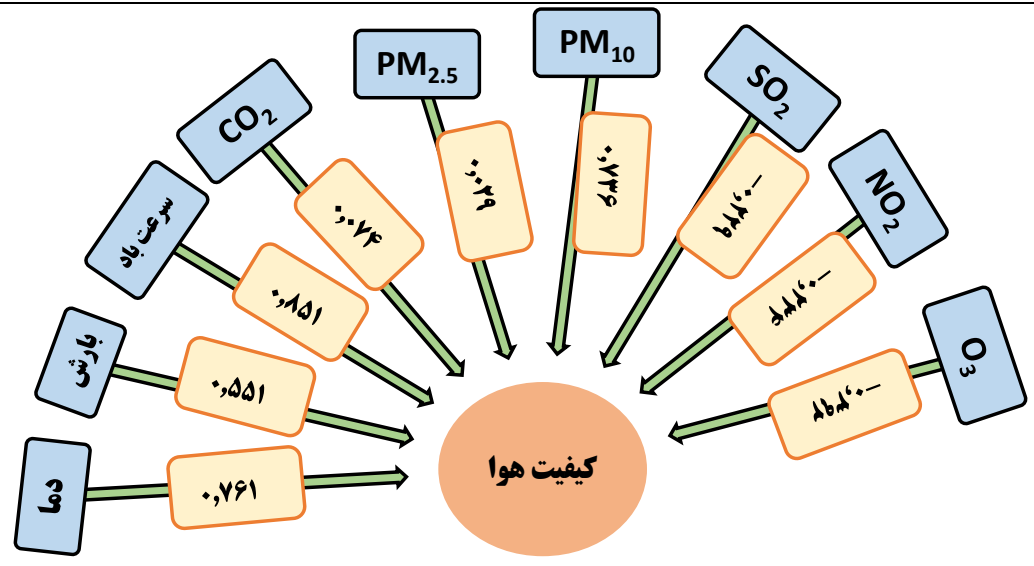

شكل 9- ضرايب بتاى تحليل مسير عوامل اثركذار بر روى شاخصهاى آلودكى هواى تهران 


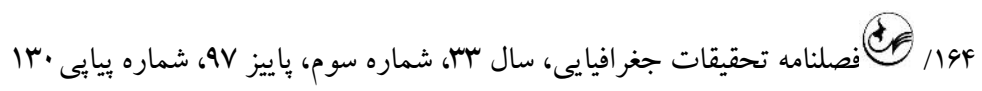

در تحليل مسير غيرمستقيم اثرات متغيرها بر كيفيت هوا نيز متغيرهاى آلودگى هوا كه در مرحله قبلى بهعنوان عامل

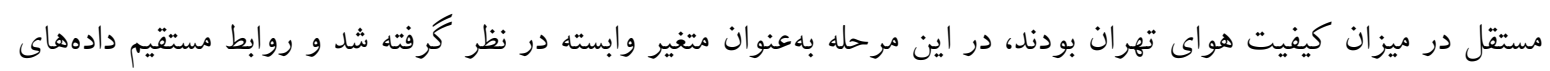

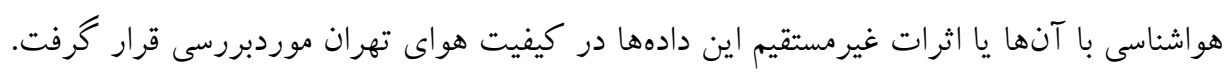

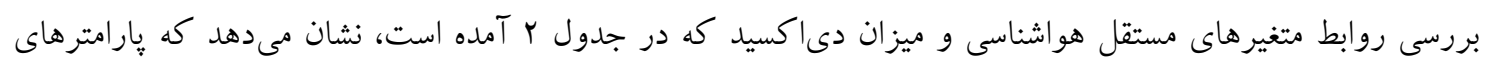

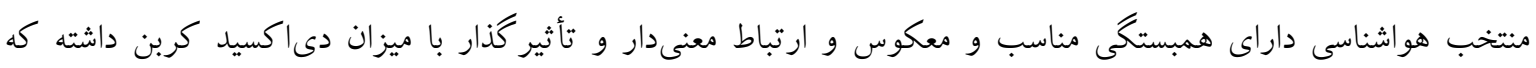

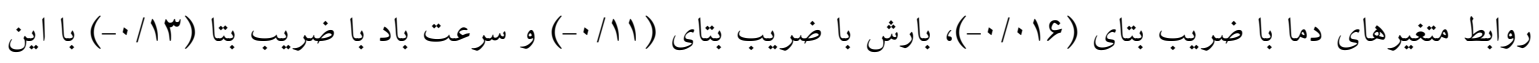

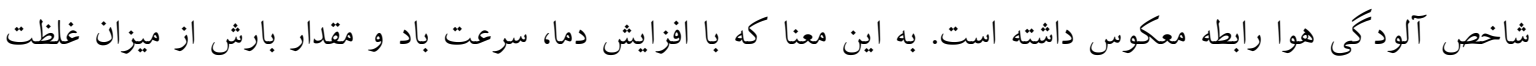

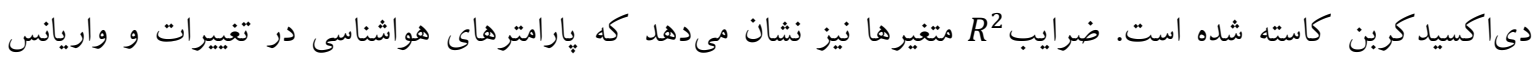
متغير دىاكسيد كربن نقش مؤثرى داشته است.

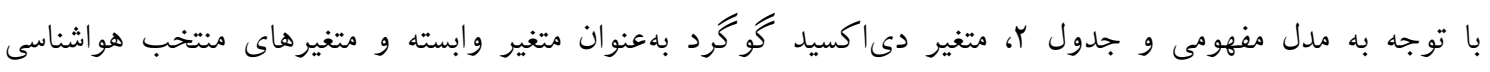

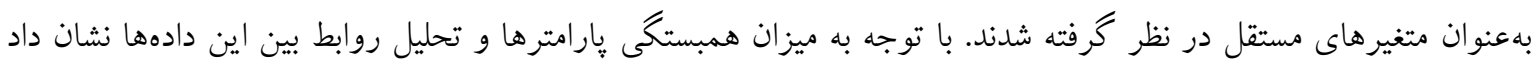

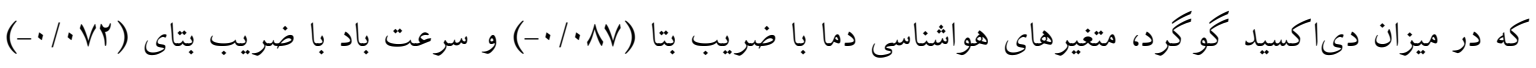

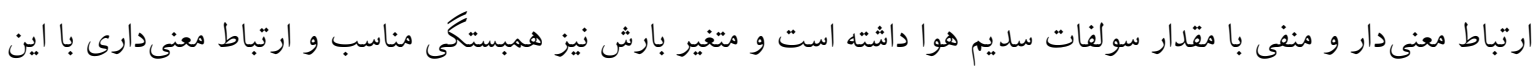
شاخص نداشته است. در بررسى عوامل تأثير كذار در متغير دىاكسيد نيتروزن مشاهده شد كه متغيرهاى مستقل دما و سرعت باد با ضرايب

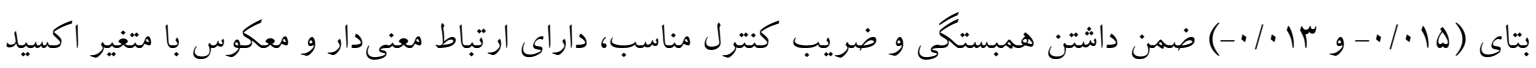

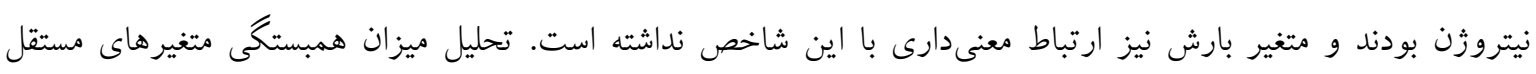

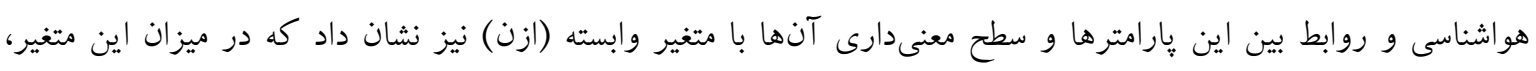

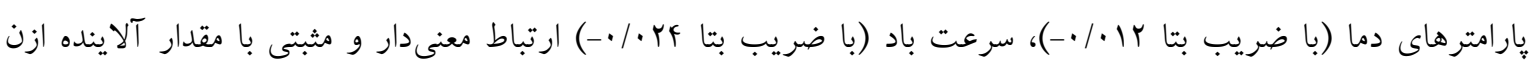

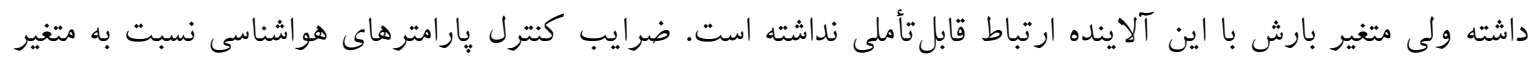

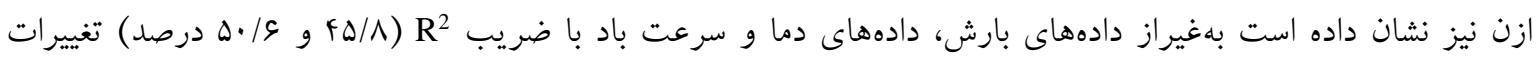
مهمىاى متغير وابسته را تعيين كردند. 
تبيين تاثيرات عناصر آبوهوايى در كيفيت هواى كلانشهر تهران/9ها

DOI: 10.29252/geores.33.3.154

جدول r - نتايج حاصل از تحليل مسير عوامل اثر كذار بر روى شاخصهاى آلود

\begin{tabular}{|c|c|c|c|c|c|c|c|}
\hline \multirow{2}{*}{ معنى دارى } & \multirow{2}{*}{ كنترل } & \multirow{2}{*}{$\begin{array}{c}\text { ضرايب رگرسيونى استاندارد شده } \\
\text { Beta }\end{array}$} & \multicolumn{2}{|c|}{ ضرايب ر ررسيونى } & \multirow{2}{*}{ ضمريبت } & \multirow[t]{2}{*}{ متغير وابسته } & \multirow[t]{2}{*}{ متغير مستقل } \\
\hline & & & Std. Error & B & & & \\
\hline$\cdot / \cdot F V$ & $F \Delta / G$ &.$- / 18$ & س & $\cdot / F D$ & $-\cdot / \& V Q$ & دع اكسيد & ين دما \\
\hline$\cdot / \cdot r q$ & $\mathrm{~m} / \mu$ & $-\cdot / / r$ & $\cdot / \cdot 99$ & $-\cdot / F V$ & -. /GYV & & سرعت باد \\
\hline.$/ \cdot r r$ & & $-\cdot / 11$ &.$/ .99$ & $-\cdot / 1 Q F$ & $-\cdot / \Delta \wedge 1$ & & ع بارش \\
\hline $.1 \cdot 41$ & $F 1 / 1$ & $-\cdot / \cdot \wedge \mathrm{V}$ & $\cdot / \cdot \mathrm{VV}$ &.$- / 199$ & $-\cdot|g| 1$ & & \\
\hline$\cdot / \cdot r V$ & $r / \mu$ & $-\cdot / \cdot V r$ & $\cdot / \cdot 11$ & $-\cdot / \mu 11$ & & & عت باد. \\
\hline$\cdot / \mid \varepsilon \wedge$ & $F / 1$ & $-\cdot / I F V$ & . I YFY & $-\cdot / \cdot 09$ & $-\cdot / r \cdot r$ & & ع بارش \\
\hline$\cdot / \cdot r$ & $F E / T$ & $-.1 \cdot 10$ & $\cdot / \cdot m$ & $-1 / \varepsilon V F$ & $-\cdot / 8 \Lambda$ & دى اكسيد & \\
\hline$\cdot / \cdot F F$ & $r V / l$ & $-\cdot / \cdot 1 r$ & $\cdot / \cdot \Lambda \Lambda$ & $-\cdot / \cdot \Delta V$ & $-\cdot / 8 \cdot 9$ & & رعت باد \\
\hline . & f & $\cdot / \cdot V G$ & $\cdot / \cdot 11$ & $\cdot / \cdot 01$ & $-\cdot / 199$ & & ع بارش \\
\hline$\cdot / \cdot r$ & $F \Delta / A$ & $-\cdot / \cdot 1 r$ & $\cdot / \cdot F D$ & I/TVQ & $-\cdot / 9 \mathrm{VV}$ & & \\
\hline$\cdot / \cdot r V$ & $0 \cdot / 8$ & $-\cdot / \cdot Y_{F}$ & $\cdot / \cdot \Delta r$ & $\cdot / \cdot \Delta f$ & $-\cdot / 211$ & ازن & سرعت باد \\
\hline.$/ 9 V F$ & $1 / 0$ & $-\cdot / \cdot r$ & r & $-\cdot / \cdot r$ & $-\cdot|| r \mid$ & & ع بارش \\
\hline $.1 \cdot 48$ & $\mathrm{Fq} / \mathrm{s}$ & $-\cdot / \cdot 1$ & $\cdot / \cdot F r$ & -.1 .90 & $-\cdot / V \cdot f$ & ذرات معلق & \\
\hline.$/$ TE & s./f & $-\cdot / \cdot a$ & $\cdot / \cdot \omega$ & $-\cdot / 1 r a$ & $-\cdot / \mathrm{VVV}$ & •ا ميك ون & رعت باد \\
\hline $.1 \cdot 49$ & $r \Delta / q$ & $-\cdot / \cdot 9$ & $\cdot / \cdot \Delta r$ & $-\cdot / 1 \cdot 4$ & $-\cdot .099$ & ין & موع بارش \\
\hline.$/ \cdot 1$ & $\mathrm{FV} / \mathrm{r}$ & $-\cdot / \cdot c_{a}$ & $\cdot / \cdot k r$ & . $/ 199$ & $\cdot / S A M$ & ذر, ات معلة & \\
\hline.$/ \cdot \Lambda$ & $f \cdot / V$ & $-\cdot / \cdot r q$ & $\cdot / \cdot 0$ & $\cdot / 1 \cdot 1$ & $-\cdot / g \mu \wedge$ & ه/ץ ميكرون & \\
\hline$\cdot 1 \cdot 49$ & $r q / 8$ & $-\cdot / \cdot V$ & $\cdot / \cdot \Delta r$ & $-\cdot / \cdot r F$ &.$- / D F F$ & & موع بارش \\
\hline
\end{tabular}

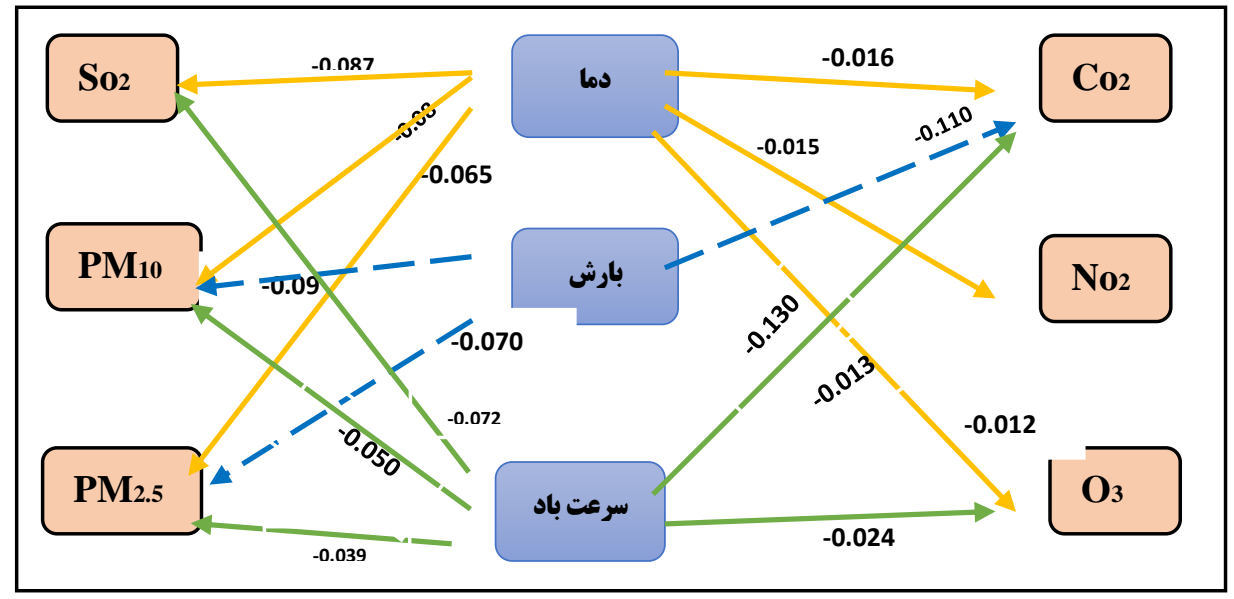

شكل V - ضرايب بتاى حاصل از تحليل مسير عوامل هواشناسى منتخب

بر روى شاخصهاى آلودىى هواى تهر ان

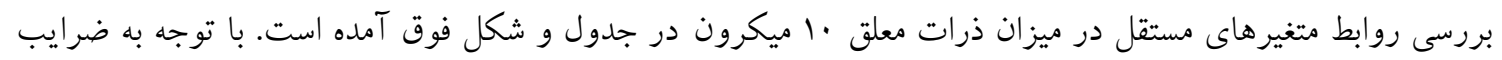

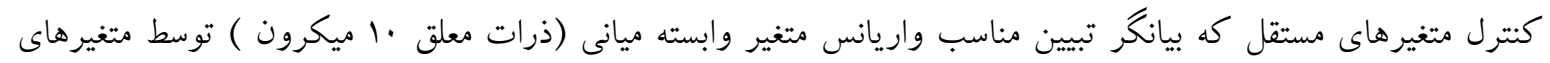
هو اشناسى مىباشد، ضرايب همبستكى دادهها نشان داده است كه همه متغيرهاى منتخب هواشناسى در ميزان اين آلاينده در 
199/ مك فصلنامه تحقيقات جغرافيايى، سال سبا، شماره سوم، باييز 9V، شماره بيايى .با شهر تهران ارتباط معنىدار و معكوس داشته است كه ضرايب بتاى آن نيز به ترتيب براى متغير دما (1٪/•) (ه)، سرعت باد

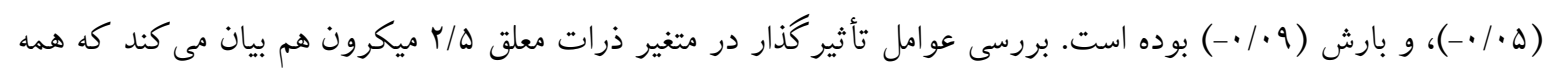

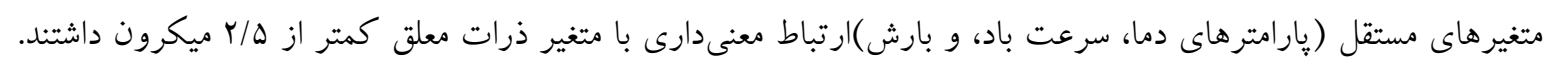

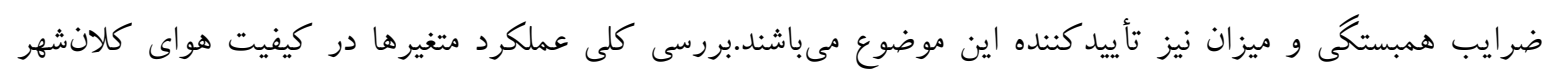

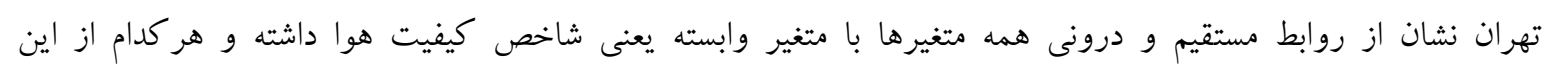

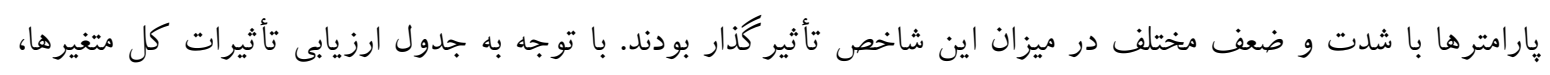

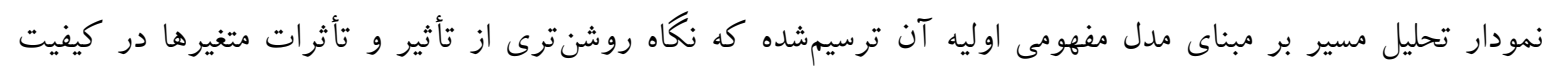

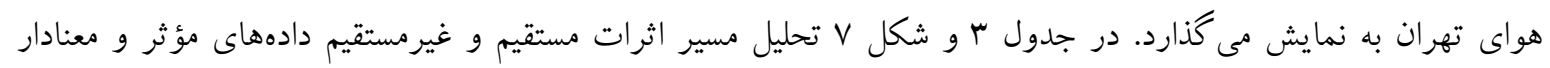

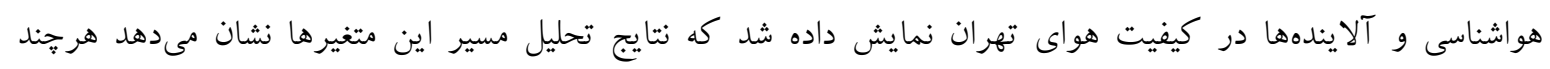

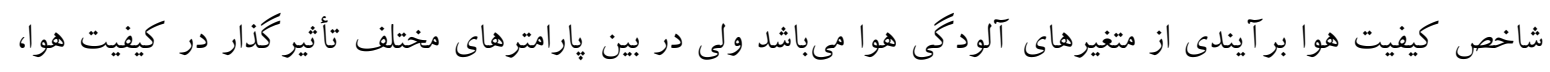

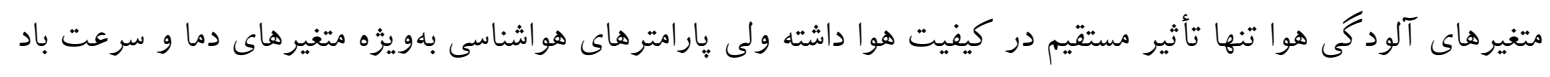

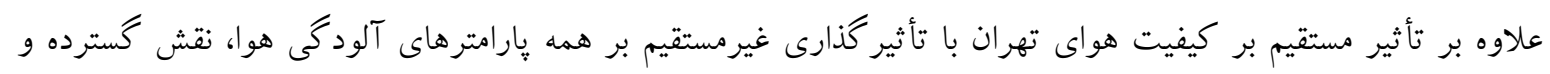
ير برنكى بر كيفيت هواى كلانشهر تهران داشتهاند.

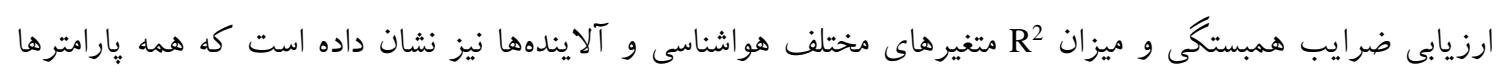

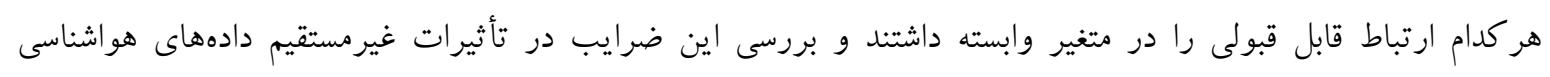

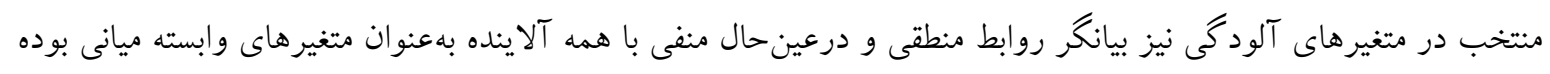

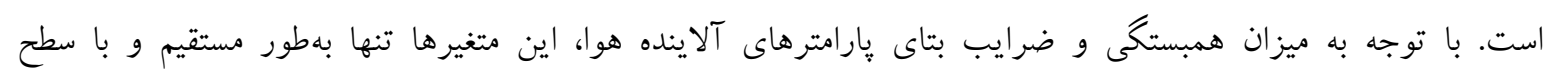

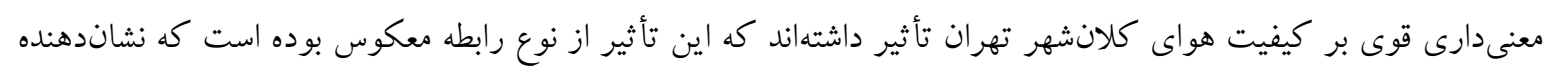

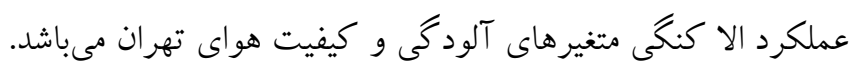

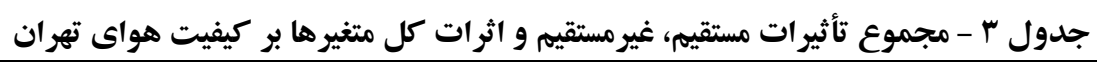

\begin{tabular}{|c|c|c|c|c|c|c|c|c|c|}
\hline \multirow{2}{*}{ تأثير } & \multicolumn{6}{|c|}{ اثرات غيرمستقيم } & \multirow[b]{2}{*}{ مستقيم } & \multirow[b]{2}{*}{ متغير مستقل } & \multirow[b]{2}{*}{ 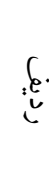 } \\
\hline & ذرات ذميكرون معلق & ذامرات معلق & 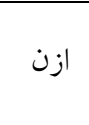 & نيتروزن & $\begin{array}{l}\text { كو گراكسيد } \\
\text { كرد }\end{array}$ & كرى كربن & & & \\
\hline$\cdot, r V V$ & $-\cdot, \cdot 9 \Delta$ & $-\cdot, \cdot \wedge$ & $\cdot,|Y|$ & $-\cdot, \cdot 10$ & $-\cdot, \cdot \wedge \mathrm{V}$ & $-\cdot, \cdot 18$ & $\cdot,|\backslash| 1$ & ميانكين دما & 1 \\
\hline$\cdot, \Upsilon \wedge \Lambda$ & $-\cdot, \cdot V$ & $-\cdot, \cdot 9$ & $\cdots$ & $\ldots$ & $\ldots$ & $-\cdot, 11$ & $\cdot, \Delta \Delta 1$ & مجموع بارش & r \\
\hline 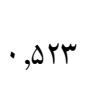 & $-\cdot, \cdot r q$ & $-\cdot, \cdot a$ & $\begin{array}{c}\cdot, \cdot Y F \\
-\end{array}$ & $-\cdot, \cdot 1 r$ & $-\cdot, \cdot V r$ & $-\cdot, \mid r$ & $\cdot, \Delta-1$ & ميانكين سرعت باد & $r$ \\
\hline$\cdot$ & $\cdots$ & $\cdots$ & $\cdots$ & $\ldots$ & $\ldots$ & $\cdots$ & $-\cdot, r 91$ & دى اكسيد كربن & f \\
\hline $\begin{array}{c}\cdot, \Lambda \Lambda S \\
- \\
\cdot, r \mu F \\
-\end{array}$ & $\ldots$ & $\cdots$ & $\cdots$ & $\ldots$ & $\ldots$ & $\cdots$ & $\begin{array}{l}-\cdot, \mid \wedge \varepsilon \\
-\cdot, Y M F\end{array}$ & دىاكسيد نيتروزن & s \\
\hline
\end{tabular}




\begin{tabular}{|c|c|c|c|c|c|c|c|c|c|}
\hline $\begin{array}{c}\cdot, \text { YTQ } \\
-\end{array}$ & $\ldots$ & $\ldots$ & $\ldots$ & $\ldots$ & $\ldots$ & $\ldots$ & $-\cdot, Y Y q$ & دى اكسيد گو گرد & v \\
\hline & $\cdots$ & $\ldots$ & $\cdots$ & $\ldots$ & $\cdots$ & $\ldots$ & ع שי, •- & ذرات معلق · اميكرون & $\wedge$ \\
\hline - & $\ldots$ & $\ldots$ & $\ldots$ & $\ldots$ & $\ldots$ & $\ldots$ & $-\cdot, \mid f r$ & ذرات معلق ه, ب ميكرون & 9 \\
\hline
\end{tabular}

مدل آمارى نهايى حاصل از تحليل مسير پارامترهاى مؤثر در كيفيت هواى تهران كه بر مبناى مدل مفهومى تحليل مسير تحقيق بوده را مىتوان در نمودار تحليل مسير (شكل ^) بيان نمود. با توجه به هدف اين يزوهش در خصوص كيفيت تأثير كذارى متغيرهاى منتخب جوى بر كيفيت هوا، همانطور كه در اين مدل ملاحظه مى شود بارامترهاى هواشناسى با تأثير مستقيم و متغيرهاى آلودىى هواى تهران پِ از تأثيريذيرى اوليه از عناصر آبوهوا شناسى در كيفيت هواى تهران تأثير كذاشته و در مدل نهايى تحليل مسير قرار مى گيرند.

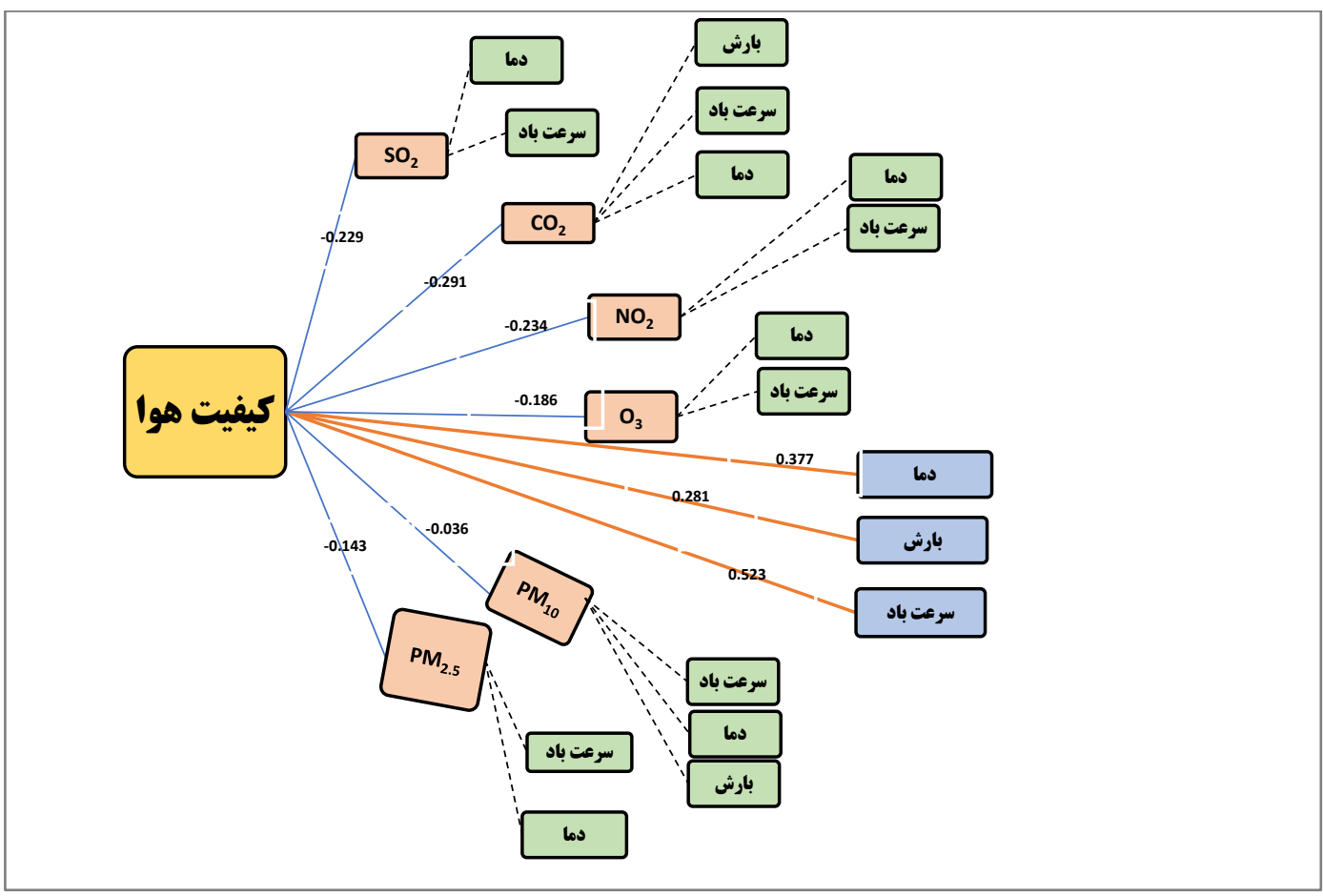

شكل1- مدل تحليل مسير تأثيرات متغيرها در كيفيت هواى تهران

نتيجه گيرى

تحليل مسير اثرات مستقيم و غيرمستقيم متغيرهاى مستقل با متغير وابسته يعنى كيفيت هواى تهران (اثرات كل متغيرها) نشان از تأثير همه متغيرها با شدت و ضعف مختلف در كيفيت هواى تهران داشته كه نقش بارز عناصر آبوهوايى در كيفيت هواى تهران را بايد در كانون توجه قرارداد، زيرا در بين همه يارامترها، متغيرهاى باد و دما با اثرات قوىتر در قياس به ساير پارامترها خودنمايى كردهاند. تأثيرات غيرمستقيم دادهاى هواشناسى بر پارامترهاى آلاينده هوا بيان از رابطه 


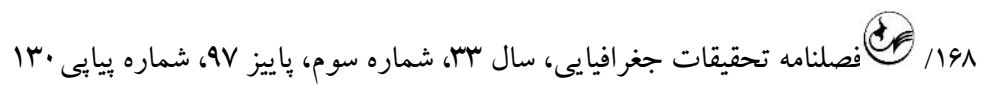

معكوس اين متغيرها با متغيرهاى هواشناسى بهويزه دما و سرعت باد مى كند بهطورى كه عملكرد ضعيف عناصر آبوهوايى

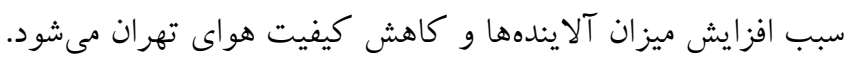

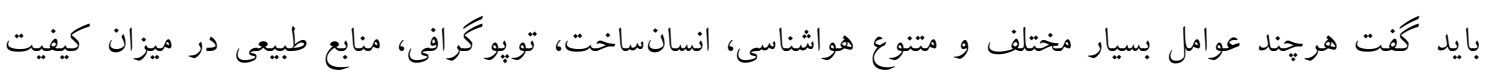

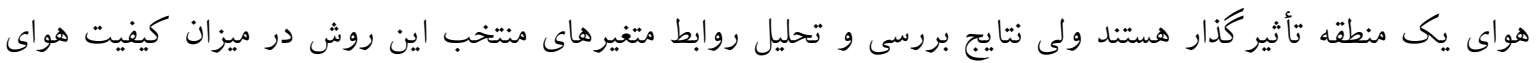

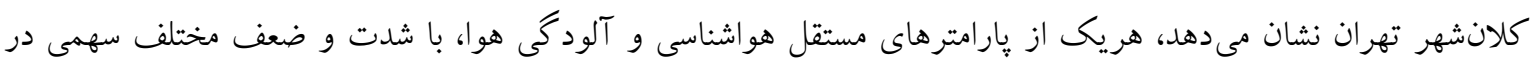

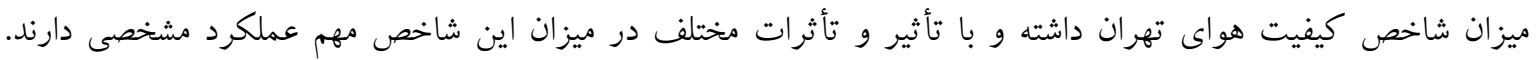

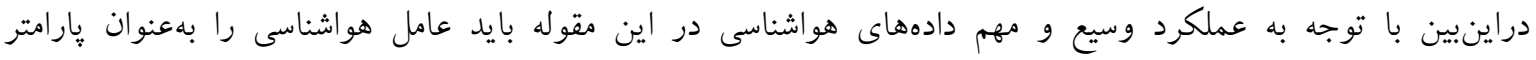

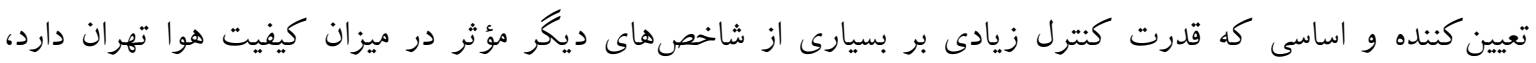

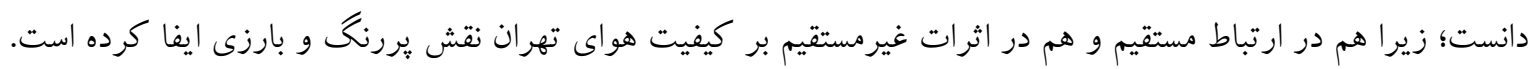

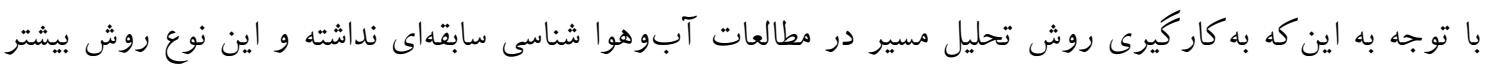

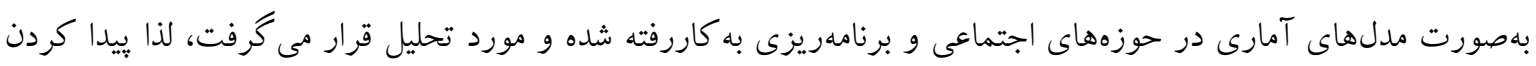

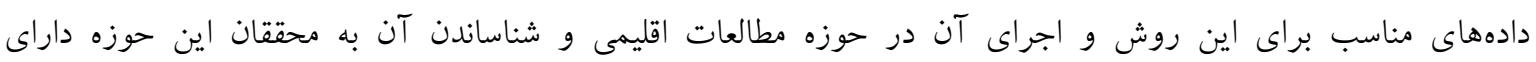

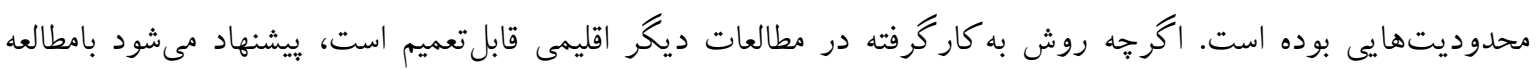

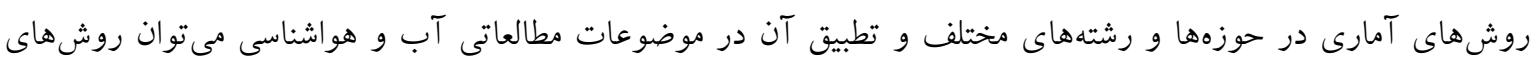
جديد در تحقيقات اقليمى را مورداستفاده قرارداد.

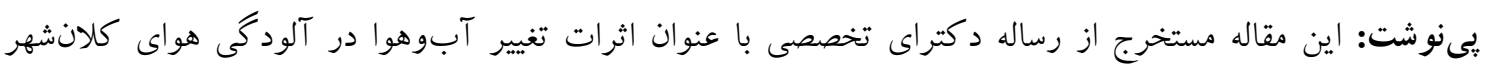

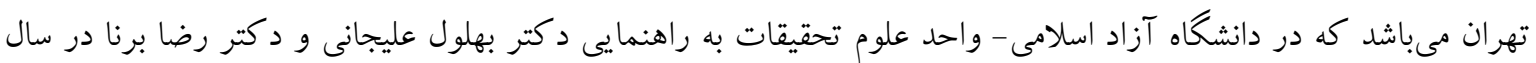

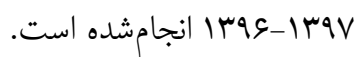

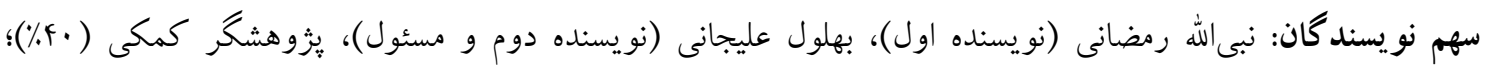

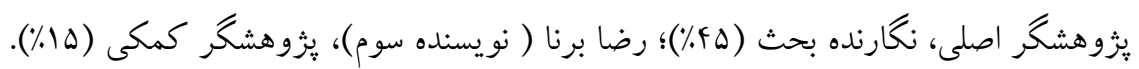

\section{منابع و مآخذ}

Abbasi Jebli, M. (2011). Investigating the air pollution process in isfahan city and its correlation with climate factors. (Master's Thesis), Faculty of Agriculture and Natural Resources, Isfahan University of Technology. (Persian)

Abbasi, M., Sari Saraf, B., \& Moghani Bileh Savar, V. (2013). Climatic factors of winter season affected by air pollutants in Tabriz city. Paper presented at the National Conference on Engineering and Agricultural Management, Environment and Sustainable Natural Resources, Hegmataneh Environmental Assessment Center, Hamedan. (Persian)

Abedini, A. (1999). The effect of sustainability on the concentration of air pollution in the city of tehran towns. (Master's Degree), Tarbiat Modares University. (Persian)

Akbari, E., Fakheri, M., Pourgholamhassan, E., \& Akbari, Z. (2015). Monthly zonation of air pollution and its relationship with climatic factors case study: Mashhad. Natural Environment, Natural Resources, 68(4), 533 - 547. [DOI:10.22059/JNE.2015.56927]. (Persian)

Bidokhti, A., \& Sharaeipour, Z. (2010). Meteorological conditions of acute air pollution episodes for Tehran. Journal of Environmental Studies, 35(52), 1-14. (Persian)

Croxford, B., Penn, A., \& Hillier, B. (1996). Spatial distribution of urban pollution: civilizing urban traffic. Science of The Total Environment, 189-190, 3-9. [DOI:10.1016/0048-9697(96)05184-4]

Doherty, R., Wild, O., Shindell, D., Zeng, G., MacKenzie, I., Collins, W., . . Schultz, M. (2013). Impacts of climate change on surface ozone and intercontinental ozone pollution: A multi-model study. Journal of Geophysical Research: Atmospheres, 118(9), 3744-3763. [DOI:10.1002/jgrd.50266] 
Entezari, A. (2003). Statistical and synoptic study of tehran air pollution. (PhD thesis), Tarbiat Moalem University of Tehran. (Persian)

Fayyaz, M. (2006). Track analysis, student statistics. Neda, 4(2), 35-43. (Persian)

Fenger, J. (1999). Urban air quality. Atmospheric Environment, 33(29), 4877-4900. [DOI:10.1016/S13522310(99)00290-3]

Frank, L. D., Stone, B., \& Bachman, W. (2000). Linking land use with household vehicle emissions in the central puget sound: methodological framework and findings. Transportation Research Part D: Transport and Environment, 5(3), 173-196. [DOI:10.1016/S1361-9209(99)00032-2]

Isa Lo, A. A., Shahmoradi, B., Bahrami, S., \& Sadat Aghamiri, M. (2011). Spatial ulnerability and air pollution crisis in metropolis. Paper presented at the Third National Conference on Urban Development, Islamic Azad University of Sanandaj, Sanandaj. (Persian)

Jacob, D. J., \& Winner, D. A. (2009). Effect of climate change on air quality. Atmospheric Environment, 43(1), 51-63. [DOI:10.1016/j.atmosenv.2008.09.051]

Javan Bakhat Amiri, S., \& Khatami, S. H. (2012). Investigating the relationship between air quality index and meteorological parameters in tehran with regression analysis. Journal of Human and Environment, 10(1), 15-28. (Persian)

Javid, M. (2012). Spatial distribution and seasonal changes of air pollutants meeting at selected meteorological stations in Tehran. (Master's Thesis), Tarbiat Modares University, Tehran. (Persian)

Johnson, R. A., \& Wichern, D. W. (1992). Applied multivariate mtatistical analysis (Fifth ed.). USA, New Jersey: Prentice-Hall.

Mahoori, R. (2012). Path analysis training in SPSS. Isfahan: Isfahan University. (Persian)

Mohammadi, H., \& Robati, M. (2009). The role of climatic parameters in the distribution of air pollution in the special economic zone of Mahshahr petrochemicals. Geography Magazine, 3(8-9), 99-121. (Persian)

Naghavi, M. (2013). Synoptic analysis of climatic elements affecting air pollution in Tehran. (Master's Thesis), Islamic Azad University. Central Tehran Branch. (Persian)

Park, D. H., Han, K. B., \& Kang, I. J. (2012). The visualization by analyzing the aelationship between the air pollutants and climatic factors using GIS. Paper presented at the International Conference on Disaster Management, Kumamoto, Japan.

Peel, J. L., Haeuber, R., Garcia, V., Russel, A. G., \& Neas, L. (2013). Impact of nitrogen and climate change interactions on ambient air pollution and human health. Biogeochemistry, 114(1-3), 121-134. [DOI:10.1007/s10533-012-9782-4]

Ren, W., Tian, H., Chen, G., Liu, M., Zhang, C., Chappelka, A. H., \& Pan, S. (2007). Influence of ozone pollution and climate variability on net primary productivity and carbon storage in China's grassland ecosystems from 1961 to 2000. Environmental Pollution, 149(3), 327-335. [DOI:10.1016/j.envpol.2007.05.029]

Roshan, G., Khosh Akhlagh, F., Negahbani, S., \& Mirkentoli, J. (2009). The effect of air pollution on climatic oscillations of tehran city. Environmental Sciences Journal, 7(1), 173-192. (Persian)

Safavi, S. Y., \& Alijani, B. (2006). Geographical factors investigating Tehran's air pollution. Geographical Researches Quarterly Journal, 38(58), 99-112. (Persian)

Saligheh, M., \& Kakhki Mahneh, H. (2015). Investigating the relationship between climate elements and air pollution fluctuations, case: Mashhad city. Geography and Environmental Hazards, 14(4), 77-94. [DOI:10.22067/geo.v4i2.31769]. (Persian)

Schaub, M., \& Paoletti, E. (2007). Introductory remarks to the special issue - XXII IUFRO World Congress, 2005 Brisbane - Air pollution and climate change: A global overview of the effects on forest vegetation. Environmental Pollution, 147(3), 429. [DOI:10.1016/j.envpol.2006.08.040]

Schweitzer, L., \& Zhou, J. (2010). Neighborhood air quality, respiratory health, and vulnerable populations in compact and sprawled regions. Journal of the American Planning Association, 76(3), 363-371. [DOI:10.1080/01944363.2010.486623]

Taghavi, H. (2011). Time and spatial distribution of air pollution indexes in Mashhad city and its effective factors. (Master's Thesis), Ferdowsi University of Mashhad. (Persian)

Taheri, A., \& Hosseini, V. (2017). Pending particles, resources, measurements and outcomes, technical report of tehran municipal air quality control (QP96 / 06/01, U / 01). Retrieved from http://air.tehran.ir/portals/0/ReportFiles/AirPollution/51.pdf

Vaseghi, E., \& Zibaei, M. (2008). Prediction of air pollution in Shiraz. Journal of Environmental Studies, 34(47), 65-72. (Persian)

Zebardast, E., \& Riazi, H. (2015). Indicators of the human environment and its effects on air pollution, case study: The perimeter of four stations of air quality measurement in Tehran city. Fine ArtsArchitecture and Urban Development, 20(1), 55-66. (Persian) 